\title{
Source and Ecological Risk Characteristics of PAHs in Sediments from Qinhuai River and Xuanwu Lake, Nanjing, China
}

\author{
Zhenhua Zhao, ${ }^{1,2}$ Zhirui Qin, $^{1}$ JingJing Cao, ${ }^{1}$ and Liling Xia ${ }^{3}$ \\ ${ }^{1}$ Key Laboratory of Integrated Regulation and Resource Development on Shallow Lake of Ministry of Education, \\ College of Environment, Hohai University, Nanjing, Jiangsu 210098, China \\ ${ }^{2}$ Department of Plant, Soil, and Microbial Sciences, Michigan State University, East Lansing, MI 48824, USA \\ ${ }^{3}$ Nanjing Institute of Industry Technology, Nanjing 210016, China \\ Correspondence should be addressed to Zhenhua Zhao; zzh4000@126.com
}

Received 13 July 2017; Revised 5 October 2017; Accepted 15 October 2017; Published 15 November 2017

Academic Editor: Andrea Gambaro

Copyright (c) 2017 Zhenhua Zhao et al. This is an open access article distributed under the Creative Commons Attribution License, which permits unrestricted use, distribution, and reproduction in any medium, provided the original work is properly cited.

In order to investigate the residual characteristics, sources, and ecological risk of PAHs in sediment from urban rivers, the sediments of 15 typical sites from Qinhuai River and Xuanwu Lake, which are typical urban rivers and lake, were collected from October 2015 to July 2016; the sources of PAHs in sediment were also identified by several methods. Results showed that $\sum$ PAHs concentration in sediment ranged from $796.2 \mathrm{ng} / \mathrm{g}$ to $10,470 \mathrm{ng} / \mathrm{g}$ with an average of 2,713.8 ng/g. High molecular weight PAHs with $4-5 \mathrm{rings}$ were most prominent in the sediment during all four seasons. Source characterization studies based on the analysis of diagnostic ratio (triangular plot method), cluster analysis, and positive factor matrix analysis suggested that the PAHs of Qinhuai River Basin were mainly from pyrogenic origin (biomass and coal combustion and vehicular emission), and the petroleum source also cannot be ignored (specially in summer). Most individual PAHs occasionally affect the aquatic organisms. The highest benzo[a]pyreneequivalent doses $\left(\mathrm{BaP}_{\text {eq }}\right.$ dose $)$ appear at the sites of sewage discharge and heavy traffic. So, the PAHs pollution sources of urban water body have obvious seasonal-dependent and human activities-dependent characteristics.

\section{Introduction}

Polycyclic aromatic hydrocarbons (PAHs), a group of typical chemicals containing two or more aromatic rings, are widely distributed in water [1], soil, sediment [2-5], and air [6]. PAHs have been attracting increasing attention, because many are known to be carcinogenic, mutagenic, or teratogenic [7, 8], which are serious health threats to organisms. Hence, United States Environmental Protection Agency (US EPA) has listed sixteen PAHs as priority pollutants. In recent years, PAHs research has focused on the distribution and source apportionment of sediments. PAHs may come from natural sources, but anthropogenic activity is generally considered the major source [9]. Anthropogenic PAHs primarily originate from pyrogenic and petrogenic sources. Pyrogenic PAHs are mainly from incomplete combustion of various fossil fuels (such as coal, oil, and natural gas), residential heating, industrial activity, wood, tobacco, and other hydrocarbons [10]. Petroleum sources also generate PAHs [11], including crude oil and refined petroleum products such as oil leakage [12].

PAHs, once produced, enter the aquatic environment via wastewater, surface runoff, atmospheric deposition, and oil leakage [13]. Due to their low water solubility, PAHs are easily adsorbed by particles and colloids when transferred into the water and sediment [14]. After settling into the sediment, PAHs will rarely photochemically and biologically oxidize and, therefore, will accumulate to high concentrations in sediments [15]. The concentration of PAHs in sediments is related to sediment type and size, geographical location, water migration, and other factors. When environmental conditions change, adsorbed PAHs may be rereleased into the water by chemical and biological processes, leading to secondary pollution of the surrounding environment $[16,17]$. Sediments act both as a reservoir and a secondary source for PAHs contamination [18].

Until recently, researches on surface sediment PAHs mainly concentrated in the estuary area of some rivers 
and lakes [19-25]. Sofowote et al. (2008) investigated the profiles and relative contributions of pollution sources to the Hamilton harbor using principal component analyses (PCA) and positive matrix factorization (PMF) methods, and results showed both methods identified four factors and gave excellent correlation coefficients between predicted and measured levels of 25 aromatic compounds; both methods predicted similar contributions from coal tar/coal combustion sources to the harbor (19 and 26\%, resp.), but PMF afforded better source identification than PCA [26]. Feng et al. (2007) studied the distribution, source, and ecological risk assessment of PAHs in suspended solids and sediment from the Yangtze River in Wuhan [27]. Chen et al. (2007) have researched the Qiantang River in the Yangtze River Delta region, mainly to analyze the temporal and spatial distribution and sources of PAHs in its water and sediments [28]. So far, relatively little research has focused on the seasonal distribution, source analysis, and ecological risk assessment of PAHs in a typical urban river [29]. Qinhuai River, a tributary of the Yangtze River, is located in the southwest of Jiangsu Province. With a total length of $110 \mathrm{~km}$ and the basin area of $2630 \mathrm{~km}^{2}$, it is the largest regional river in Nanjing. Internal Qinhuai River is a typical urban river, flowing across the Nanjing city, which directly affected the sustainable economic development of Nanjing city. Xuanwu Lake is the largest shallow lake of Nanjing $\left(3.7 \mathrm{~km}^{2}\right)$, a typical urban shallow lake, which has been subjected to a series of human disturbances, such as the inflow of domestic sewage, surface rain runoff from the surrounding residents and mountain, water diversion from drink water treatment plant $\left(1.8 \times 10^{5} \mathrm{t} / \mathrm{d}\right)$, tourist entertainment, and rubbish in lake park. The objective of this article is to explore the applicability of source appointment technologies and the effects of city activities on the distribution and ecological risk of PAHs in surface sediments, provide theoretical support for the pollution sources controlling and desilting treatment, and make most of PAHs removed from the river, to reduce the ecology risk of urban river and lake.

\section{Material and Methods}

2.1. Sampling Region and Sites. A map showing the location of the sampling sites is provided in Figure 1. Corresponding functional regional characteristics are shown in Table 1 . Sediment sampling was carried out along the inner Qinhuai River and Xuanwu Lake in four seasons. The sampling time, based on local seasons, is grouped as follows: autumn (October, 2015), winter (January, 2016), spring (April, 2016), and summer (July, 2016). The middle month of different season was chosen as the typical month of sampling. According to the statistical data estimated by local government, the sedimentation rate is about $10 \mathrm{~cm}-60 \mathrm{~cm}$ a year for different river. Moreover, the sampling tool is the grab sampler, so the sediment samples can be used as representative samples of different seasons. Surface sediment sampling was collected by grab sampler. Each sample consisted of central parts of 5 subsamples randomly collected at 5 points within the study area. The samples were placed into the sampling bottles, sealed and stored at $-20^{\circ} \mathrm{C}$ in the refrigerator for further analysis.
2.2. PAH Extraction, Cleanup, and Determination. For PAHs analysis, sediments were freeze-dried, crushed into fine powders, and passed through a 100-mesh sieve. Five grams of sieved samples was mixed with $2 \mathrm{~g}$ anhydrous sodium sulfate and ultrasonic-extracted for $10 \mathrm{~min}$ with $15 \mathrm{~mL} n$-hexane: acetone $(2: 1 \mathrm{~V} / \mathrm{V})$ after soaking for $1 \mathrm{~h}$. The supernatant was transferred to a pear-shaped flask; then the residual sediment was ultrasonic-extracted again with $15 \mathrm{~mL} n$-hexane: dichloromethane $(3: 1 V / V)$ as described above. All the supernatant was combined to a $50 \mathrm{~mL}$ pear-shaped flask and concentrated to about $1 \mathrm{~mL}$ by vacuum rotary evaporation apparatus (RE-3000, Yarong Biochemical Instrument Plant, Shanghai, China). For purification, the concentrate was transferred to solid phase extraction column (upper: $1.0 \mathrm{~g}$ anhydrous sodium sulfate; the second layer is $0.5 \mathrm{~g}$ copper, the third layer is $1 \mathrm{~cm}$ silica gel, and $1 \mathrm{~cm}$ neutral alumina is at bottom) (Borui Co., Ltd., Tianjin, P. R. China) rinsed with $5 \mathrm{~mL} n$-hexane, which had been rinsed with $5 \mathrm{~mL} n$ hexane with a drop-wise flow rate. The column was eluted with a mixture of $25 \mathrm{~mL} n$-hexane: dichloromethane ( $3: 1$, $V: V)$. The eluent was collected into a pear-shaped flask and concentrated to $1 \mathrm{~mL}$ for HPLC determination.

Among the reagents, acetone, $n$-hexane, and copper powder were analytical reagent; anhydrous sodium sulfate was guaranteed reagent grade (Nanjing Chemical Reagent Limited Company, Nanjing, China); neutral alumina was chromatographically pure (Shanghai Ludu Chemical Reagent Plant, Shanghai, China).

Test equipment was the high-performance liquid chromatography (HPLC) of Agilent 1100 HPLC with fluorescence (FLD) and UV-adsorption detector (Agilent Technologies, Palo Alto, USA). The column was Agilent ZORBAX EclipseXDB-C18 $(4.6 \times 250 \mathrm{~mm}, 5 \mu \mathrm{m})$. Chromatographic conditions: mobile phase was acetonitrile and water; the initial conditions was acetonitrile: water $(6: 4, V: V)$ and then linear elution to $100 \%$ acetonitrile at the rate of $0.75 \mathrm{~mL} / \mathrm{min}$ within $60 \mathrm{~min}$. Detection of wavelength was carried out: time programming with FLD signals, $0-9 \min : \operatorname{Ex} \lambda=260 \mathrm{~nm}$ and $\operatorname{Em} \lambda=380 \mathrm{~nm} ; 9-16 \mathrm{~min}: \operatorname{Ex} \lambda=260 \mathrm{~nm}$ and $\operatorname{Em} \lambda=340 \mathrm{~nm}$; 16-18 min: $\operatorname{Ex} \lambda=260 \mathrm{~nm}$ and $\operatorname{Em} \lambda=380 \mathrm{~nm} ; 18-21 \mathrm{~min}: \operatorname{Ex} \lambda$ $=260 \mathrm{~nm}$ and $\operatorname{Em} \lambda=380 \mathrm{~nm} ; 21-23 \mathrm{~min}: \operatorname{Ex} \lambda=289 \mathrm{~nm}$ and $\operatorname{Em} \lambda=462 \mathrm{~nm} ; 23-30 \mathrm{~min}: \operatorname{Ex} \lambda=320 \mathrm{~nm}$ and $\operatorname{Em} \lambda=380 \mathrm{~nm}$; 30-36 min: $\operatorname{Ex} \lambda=266 \mathrm{~nm}$ and $\operatorname{Em} \lambda=403 \mathrm{~nm} ; 36-52 \mathrm{~min}$ : $\operatorname{Ex} \lambda=294 \mathrm{~nm}$ and $\operatorname{Em} \lambda=430 \mathrm{~nm} ; 52 \mathrm{~min}: \operatorname{Ex} \lambda=290 \mathrm{~nm}$ and $\operatorname{Em} \lambda=500 \mathrm{~nm}$. PAHs were quantified by using external standard solutions obtained from Dr. Ehrenstorfer $\mathrm{GmbH}$ (Augsburg, Germany).

The investigated PAHs in this study included naphthalene (Nap), acenaphthylene (Ace), fluorene (Flu), phenanthrene (Phe), anthracene (Ant), fluoranthene (Fla), pyrene (Pyr), benzo[a]anthracene $(\mathrm{BaA})$, chrysene $(\mathrm{Chr})$, benzo[b]fluoranthene $(\mathrm{BbF})$, benzo[k]fluoranthene $(\mathrm{BkF})$, benzo[a]pyrene $(\mathrm{BaP})$, dibenzo[a,h]anthracene $(\mathrm{DahA})$, and benzo[g,h,i]perylene (BghiP).

2.3. Quality Control. In order to ensure the accuracy and precision of experimental data, replicate samples, certified reference materials HS-5 (sediments, provided by NRCIMB of Canada), matrix spikes samples (sediment samples of 


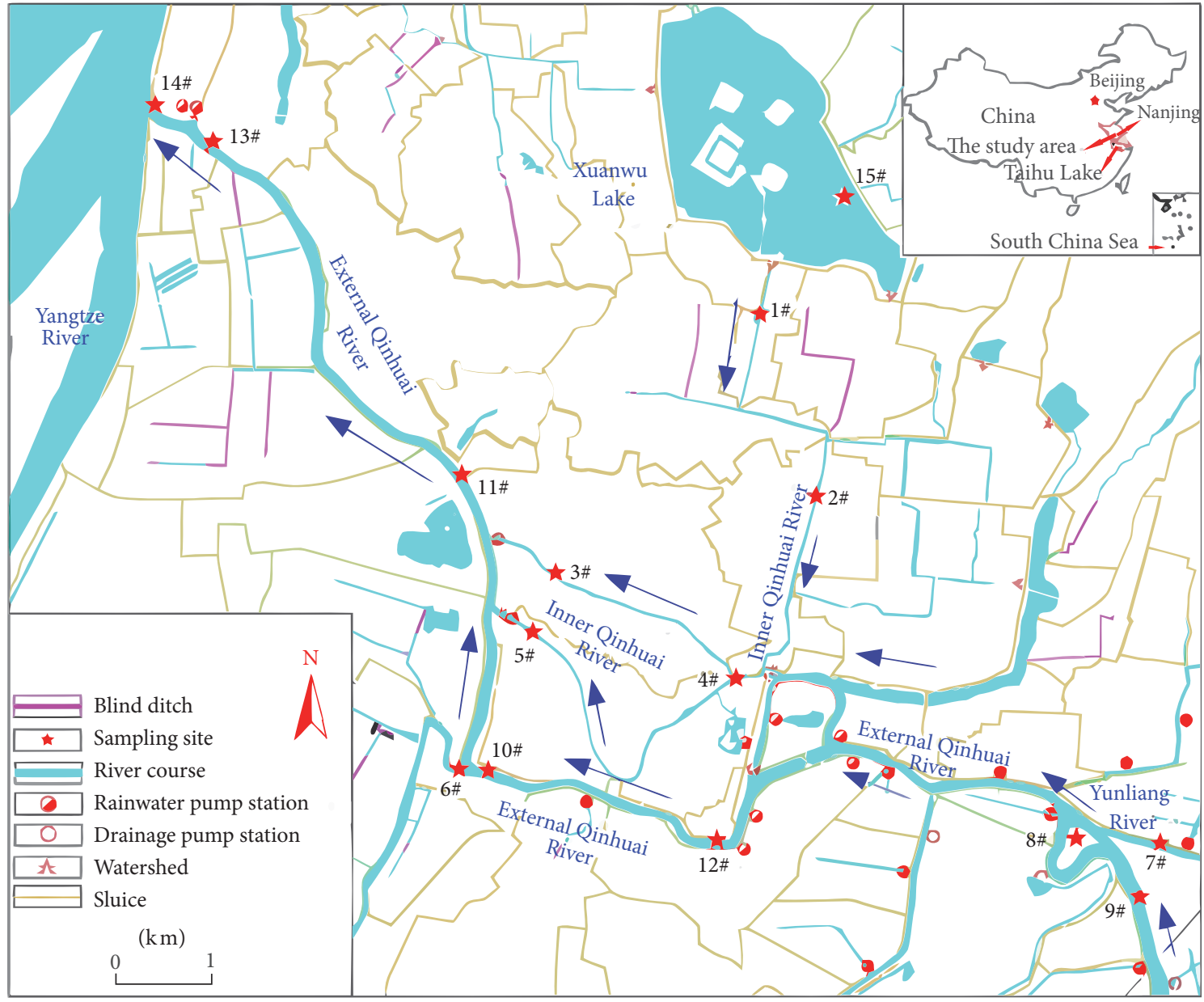

FIgUre 1: Sampling sites in the study area in Nanjing City, China. The codes for each sampling site are given in Table 1.

known PAH levels spiked with a mixture consisting of $1 \mu \mathrm{g}$ each of PAHs), and procedural blanks were used as quality control procedures. Analyses were run in batches of $10 \mathrm{sam}$ ples plus four quality controls (QCs) including one reagent blank, one matrix blank, one matrix spikes sample, and one random sample in duplicate. No detectable amounts of target PAHs are detected in the blanks. The recovery efficiency of PAHs ranged from $89 \%$ to $111 \%$ for HS-5 and from $78 \%$ to $105 \%$ for the spiked samples with relative standard deviation (RSD) $3.2 \%-10.6 \%$. The method detection limits were in the range of $0.5-2.0 \mathrm{ng} \mathrm{g}^{-1}$ dry weight. The accuracy and precision with $\mathrm{PAHs}$ are within $8 \%$ variability for both $10 \mathrm{ng} / \mathrm{ml}$ and $200 \mathrm{ng} / \mathrm{ml}$ concentrations. PAHs standard solution was diluted with acetonitrile; six concentrations of the mixed standard were configured to quantify peak area by establishing a working curve with external standard method, and the correlation of the standard curve was above 0.99. All of the measurements were performed in triplicate, the results were not corrected according to the percent recovery of HS5 , spiked samples, and blanks, and the means were used for calculations.

2.4. Positive Matrix Factorization (PMF). The PMF model, developed by Paatero and Tapper [30], is one of the typical factor analysis models. PMF is a useful factorization method that can calculate source profile and contribution. Unlike the traditional factor analysis models, PMF model utilizes nonnegativity constraints for obtaining physically realistic meanings [31].

The principle of the PMF model is to factor the initial $n \times m$ data matrix $X$ ( $n$ : number of samples; $m$ : number of species) into $(n \times p)$ matrices $G$ (source contributions) and $(p \times m)$ matrices $F$ (source profiles), as well as the "residual matrix" $E(n \times m)$ firstly, as follows:

$$
E=X-G F,
$$

where $G$ is the source contribution matrix, $F$ is the source profile matrix, and $p$ is the number of sources [31]. Certainly, the elements of $G$ and $F$ are constrained to nonnegative values.

The elements $e_{i j}$ of matrix $E(n \times m)$ indicate the residual value not accounted for by the modeled data value $x_{i}$.

$$
x_{i j}=\sum_{k=1}^{p} g_{i k} f_{k j}+e_{i j}
$$

where $x_{i j}$ is the $j$ th species concentration measured in the $i$ th sample, $g_{i k}$ is the $k$ th source's contribution to sample $i$, and $f_{k j}$ 
TABLE 1: Sampling sites and the corresponding regional characteristics.

\begin{tabular}{|c|c|c|c|c|}
\hline Reach & Code & Position & $\begin{array}{l}\text { Sedimentation } \\
\text { rate a year }\end{array}$ & Regional characteristics \\
\hline $\begin{array}{l}\text { Northern section of } \\
\text { IQR }\end{array}$ & $1 \#$ & Zhenzhu Bridge & \multirow{2}{*}{$30-40 \mathrm{~cm}$} & \multirow{2}{*}{$\begin{array}{l}\text { Near the main road and downtown of city, there are } \\
\text { floating contaminations. }\end{array}$} \\
\hline $\begin{array}{l}\text { Eastern section of } \\
\text { IQR }\end{array}$ & $2 \#$ & Yixian Bridge & & \\
\hline \multirow[b]{2}{*}{ Middle of IQR } & $3 \#$ & Wenjin Bridge & \multirow[b]{2}{*}{$50-60 \mathrm{~cm}$} & $\begin{array}{l}\text { Locates at Chaotian Temple, receiving sewage } \\
\text { discharge, with slow water flow due to gate controlling. }\end{array}$ \\
\hline & $4 \#$ & Wenzheng Bridge & & $\begin{array}{c}\text { Receives incoming water from eastern section of } \\
\text { Internal Qinhuai River, representing water quality of } \\
\text { Qinhuai scenic zone. }\end{array}$ \\
\hline $\begin{array}{l}\text { Southern section of } \\
\text { IQR }\end{array}$ & $5 \#$ & Xiafu Bridge & $40-50 \mathrm{~cm}$ & $\begin{array}{l}\text { Receives sewage discharges and commercial } \\
\text { contaminations }\end{array}$ \\
\hline Nanhu Lake Area & $6 \#$ & Saihong Bridge & $50-60 \mathrm{~cm}$ & $\begin{array}{l}\text { A typical black and odorous river near urban arterial } \\
\text { road. }\end{array}$ \\
\hline \multirow[b]{2}{*}{ Yunliang River Area } & $7 \#$ & Yunliang River & $10-30 \mathrm{~cm}$ & $\begin{array}{l}\text { Receiving the tail water of sewage treatment plant, it is } \\
\text { the local Sewage River. }\end{array}$ \\
\hline & $8 \#$ & Wetland Park & $10-20 \mathrm{~cm}$ & $\begin{array}{l}\text { Locates between the downstream of Yunliang River and } \\
\text { External Qinhuai River, belonging to the main body } \\
\text { water of Qiqiaoweng Wetland Park }\end{array}$ \\
\hline $\begin{array}{l}\text { Upstream of Qinhuai } \\
\text { River }\end{array}$ & 9\# & External Qinhuai River & $20-30 \mathrm{~cm}$ & The upstream incoming water of urban water body. \\
\hline \multirow{5}{*}{$\begin{array}{l}\text { External Qinhuai } \\
\text { River }\end{array}$} & $10 \#$ & Fengtai Bridge & \multirow{5}{*}{\multicolumn{2}{|c|}{$\begin{array}{l}\begin{array}{l}\text { Subject to the disturbance of traffic and commercial } \\
\text { activities with stable flow volume and concrete } \\
\text { revetment. }\end{array} \\
\text { The estuary of External Qinhuai River into the Yangtze } \\
\text { River. }\end{array}$}} \\
\hline & $11 \#$ & Hanzhongmen Bridge & & \\
\hline & $12 \#$ & Yuhua Bridge & & \\
\hline & $13 \#$ & Inside of the Sancha estuary & & \\
\hline & $14 \#$ & Outside of the Sancha estuary & & \\
\hline Xuanwu Lake & $15 \#$ & Xuanwu Lake & $20-30 \mathrm{~cm}$ & $\begin{array}{l}\text { Receiving the water diversion from drink water } \\
\text { treatment plant }\left(1.8 \times 10^{5} \mathrm{t} / \mathrm{d}\right)\end{array}$ \\
\hline
\end{tabular}

Note. IQR: Internal Qinhuai River.

is the $j$ th element's concentration in source $k . e_{i j}$ is the residual associated with the $j$ th species concentration measured in the ith sample.

The objective function $(Q)$ related to the residual and uncertainty is minimized using weighted least-squares by PMF, which is defined as

$$
Q(E)=\sum_{i=1}^{m} \sum_{j=1}^{n}\left(\frac{e_{i j}}{\sigma_{i j}}\right)^{2},
$$

where $n$ and $m$ are the number of samples and species, respectively; $p$ represents the number of factors extracted; $i=1,2, \ldots, n$ samples; $j=1,2, \ldots, m$ species; $k=1,2, \ldots, p$ sources. $e_{i j}$ is the difference between the observations and the model; $u_{i j}$ is the uncertainty for each observation. The PMF solution minimizes the object function $Q$ based upon the given uncertainty $u$ [32]. The uncertainties for each sample were calculated using measurement uncertainties (MU percent) and method detection limits (MDLs). A discussion of calculating uncertainties is provided by Reff et al. (2007) [33] and USEPA (2008) [21]. If the concentration $\leqslant$ MDL, the uncertainty $u$ is calculated as [34]

$$
u=\frac{5}{6} \times \mathrm{MDL}
$$

and when the concentration $>$ MDL, $u$ is calculated as

$$
u=\sqrt{(\mathrm{MU} \times \text { concentration })^{2}+(0.5 \times \mathrm{MDL})^{2}} .
$$

In this study, the EPA PMF 5.0 model was used [21].

\section{Results and Discussion}

\subsection{Temporal and Spatial Characteristics}

3.1.1. Temporal and Spatial Characteristics of the $\sum P A H s$ in Sediments. Table 2 shows the residue characteristic of 14 PAHs in sediments from Qinhuai River. $\sum$ PAHs concentrations in sediments ranged between $796.2 \mathrm{ng} / \mathrm{g}$ and 10,470 ng/ $\mathrm{g}$, with a mean of $2,713.8 \mathrm{ng} / \mathrm{g}$. Compared to several studies reported elsewhere (Table 3), mean concentration of $\sum$ PAHs in sediments from Qinhuai River was found to be lower than that from Calabar River (9,370 ng/g), Nigeria [35], and Haihe River, Tianjin, China (27,074.1 ng/g) [36]. The maximum concentration in this study was lower than that in sediments of Haihe River (16,901 ng/g) in 2014 [29], but mean concentration was higher than other rivers. Owing to extensive economic and industrial development in Nigeria, the concentration of $\sum$ PAHs in Calabar River was higher than 


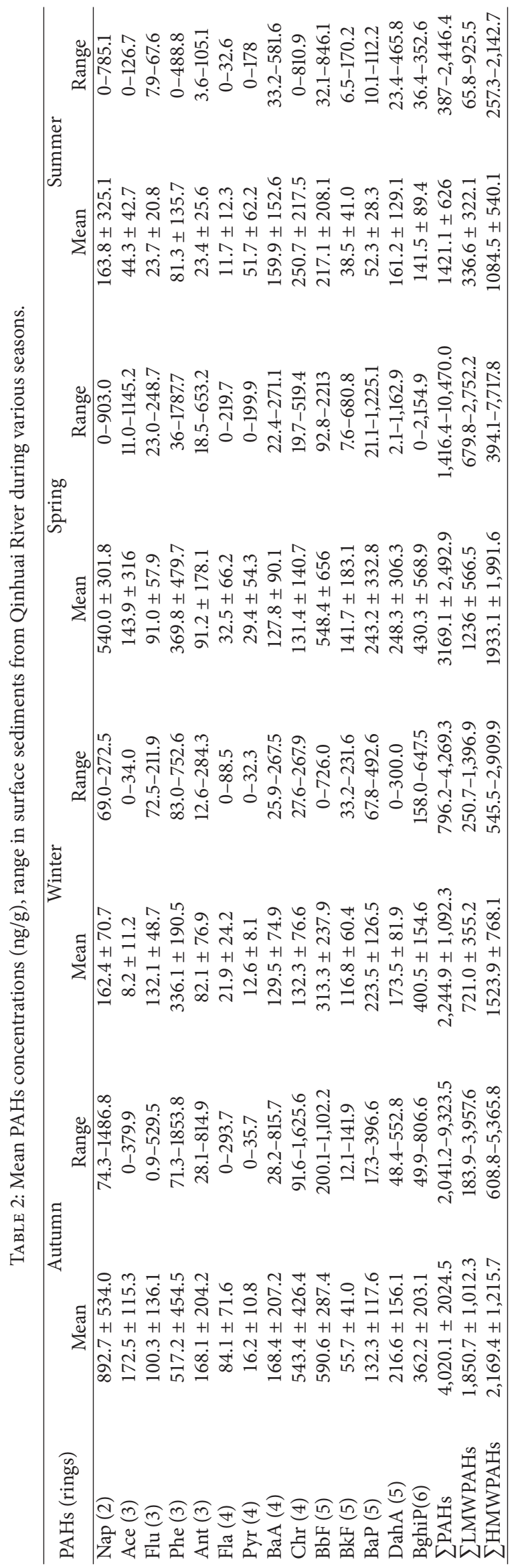


TABLE 3: Sediment PAHs concentrations reported from elsewhere.

\begin{tabular}{|c|c|c|c|c|}
\hline Study areas & $\begin{array}{l}\text { Number } \\
\text { of PAHs }\end{array}$ & $\begin{array}{l}\sum \text { PAHs Conc. } \\
\text { (ng/g) }\end{array}$ & $\begin{array}{l}\text { Mean } \\
(\mathrm{ng} / \mathrm{g})\end{array}$ & References \\
\hline Qinhuai River, Nanjing, China & 14 & $796.2-10,470$ & $2,713.8$ & This study \\
\hline Qiantang River, China & 15 & $91.3-614.4$ & 313.3 & Chen et al. 2007 [28] \\
\hline Songhua River, China & 15 & $20.5-632.0$ & 178.0 & Ma et al. 2013 [25] \\
\hline Songhua River, China & 16 & $68.25-654.15$ & 234.15 & Zhao et al. 2014 [23] \\
\hline Arc River, France & 16 & $151.0-1,257.0$ & 585.3 & Kanzari et al. 2012 [40] \\
\hline Haihe River, China & 16 & $257.0-16,901.0$ & - & Chen et al. 2014 [29] \\
\hline Calabar River, Nigeria & 17 & $1,670.0-20,100.0$ & 9,370 & Oyo-Ita et al. 2013 [35] \\
\hline Tuhai-Majia River, China & 16 & $311.7-3,736.3$ & 914.4 & Liu et al. 2012 [37] \\
\hline Haihe River, Tianjin, China & 16 & $774.8-255,371.9$ & $27,074.1$ & Jiang et al. 2007 [36] \\
\hline Nilufer Creek, Bursa, Turkey & 12 & $15.0-9,600.0$ & - & Karaca and Tasdemir, 2014 [41] \\
\hline Luan River, China & 16 & $20.9-287.0$ & 115.3 & Cao et al. 2010 [42] \\
\hline Yangtze River, Wuhan, China & 16 & $72.4-3,995.2$ & $1,334.5$ & Feng et al. 2007 [27] \\
\hline Tonghui River, Beijing, China & 16 & 127.1-927.7 & 540.4 & Zhang et al. 2004 [22] \\
\hline Rivers in Shanghai, China & 17 & $107.0-1,707.0$ & 823.0 & Liu et al. 2008 [24] \\
\hline Boston Harbor, USA & 4 & $0.4-6300$ & - & McGroddy et al. 1995 [43] \\
\hline Malacca Strait, Malaysia & 16 & $347.05-6207.5$ & - & Keshavarzifard et al. 2017 [44] \\
\hline Djibouti-city coastal area, Djibouti & 16 & $2.65-3760.11$ & 387.87 & Mahdi ahmed et al. [45] \\
\hline $\begin{array}{l}\text { The coastal lagoons and estuaries of } \\
\text { New York and New Jersey, USA }\end{array}$ & - & $7.6-6766.1$ & 468.4 & Potapova et al. 2016 [46] \\
\hline Pengkalan Chepa River, Malaysia & 16 & $36.7-560.7$ & 266.5 & Noor et al. 2015 [47] \\
\hline Sydney Harbor, Australia & - & Bd-460336 & 21782 & Birch 2017 [48] \\
\hline
\end{tabular}

that in Qinhuai River [35]. The average content $(27,074.1 \mathrm{ng} / \mathrm{g})$ of $\sum$ PAHs in the sediment of Haihe River is about ten times that of Qinhuai River $(2,713.8 \mathrm{ng} / \mathrm{g})$; this result could be attributed to the fact that Tianjin was an old and established industrial city with the largest port in north China [37], along with rapid development of the petrochemical industry, the iron and steel industry, and other heavy industries and rapid urbanization [36]. In addition to Luan River as a water source with an average of $115.3 \mathrm{ng} / \mathrm{g}, \sum$ PAHs levels of other rivers were relatively high, which were closely related to the economic development and industrialization. Qinhuai River is a typical urban river through the densely populated city of Nanjing; sewage discharges and industrial pollution emissions lead to higher mean concentration of $\sum$ PAHs than other rivers apart from Calabar River and Haihe River.

As shown in Table 2 and Figure 2(b), average concentrations of $\sum$ PAHs in sediments were found to be as follows: autumn $(4020.1 \mathrm{ng} / \mathrm{g})>\operatorname{spring}(3,169.1 \mathrm{ng} / \mathrm{g})>$ winter $(2244.9 \mathrm{ng} / \mathrm{g})>\operatorname{summer}(1421.1 \mathrm{ng} / \mathrm{g})$, indicating that the worst sediment contamination by PAHs appeared in autumn. The uneven seasonal distribution of PAHs in sediments could be attributed to the difference of rainfall and temperature in different seasons. Strong rainfall can scour the surface, carrying the PAHs into the river [38]; high temperature could lead to their subsequent evaporation and degradation [39]. So the least concentration of PAHs appeared in summer.

From Table 1 and Figure 2(a), PAHs of different sampling sites were quite spatially different. High levels of PAHs at sampling sites $1 \#, 3 \#, 4 \#, 5 \#$, and $7 \#$ may be related to the inputs of surrounding pollution [49]. For example, 7\# is located in Yunliang River, receiving the tail water from eastern-city's sewage treatment plant, while 3\# and 4\#, located in the middle of Internal Qinhuai River, received polluted incoming water from eastern section of Internal Qinhuai River, contributing to the high PAHs concentrations detected. High concentration PAHs was also found at site 5\#, which was in the southern section of Internal Qinhuai River, and the discharges of sewage and markets sewage were observed during the sampling period. The low concentration in site 8\#, located in Qiqiaoweng Wetland Park between the downstream of Yunliang River and External Qinhuai River, might be related to the clean incoming water of upper reaches from External Qinhuai River and natural self-cleaning function of wetlands in park. Overall, mean concentrations of $\sum$ PAHs in sediments from Internal Qinhuai River (from sites 1\# to 5\#) were higher than that from External Qinhuai River, and because Internal Qinhuai River flows through the urban center, frequent human activities lead to more pollution input and the deposition of PAHs in sediments caused by the low-flow rate due to the gate-control and stagnation. It is worth mentioning that the relatively low concentration $\sum$ PAH found at the estuary (site 14\#) may be attributed to the fact that this site is far from anthropogenic pressure and the probable tidal flushing of pollutants adsorbed on sediment particles. So, human activities are the main pollution source of PAHs for urban water body. This result is consistent with the view of Oyo-Ita et al. [35]. 

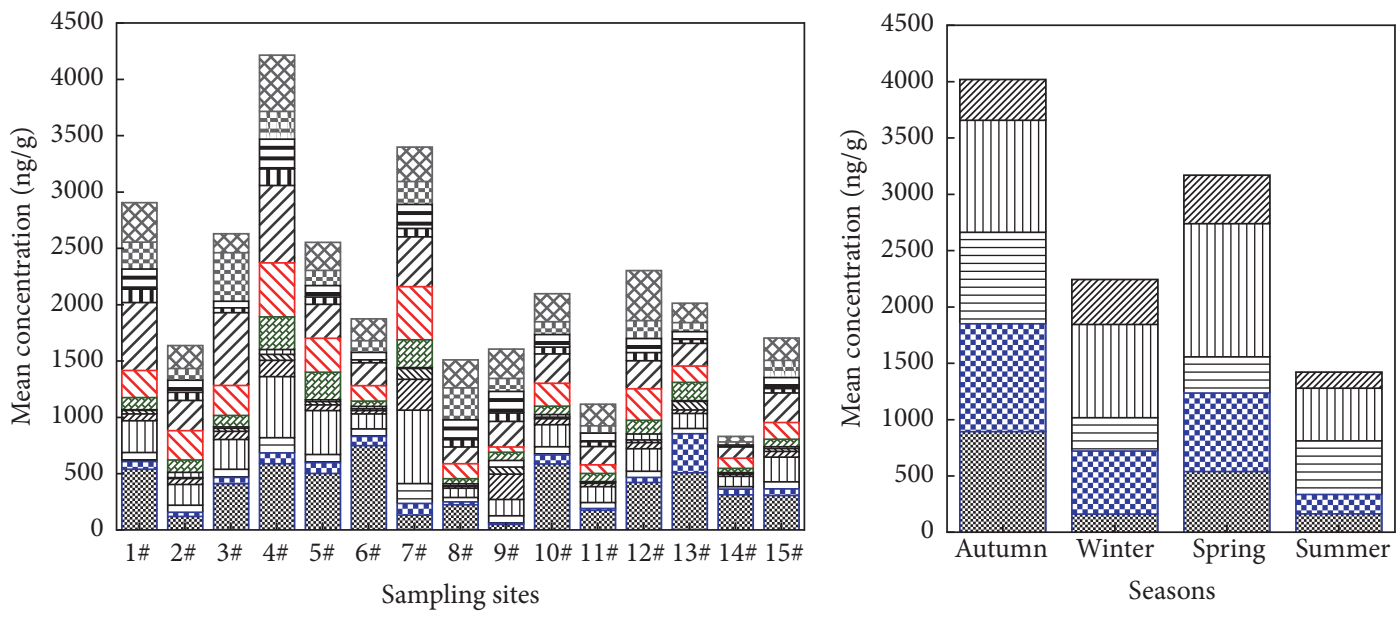

\begin{tabular}{|c|c|c|}
\hline Nap & Fla & W BkF \\
\hline 80 Ace & 畐 Pyr & $E \mathrm{BaP}$ \\
\hline 寻 Flu & $\mathrm{BaA}$ & BahA \\
\hline 向 Phe & $\triangle \mathrm{Chr}$ & B BghiP \\
\hline $\mathbb{Z}$ Ant & $\nabla Z \mathrm{BbF}$ & \\
\hline
\end{tabular}

(a)

(b)

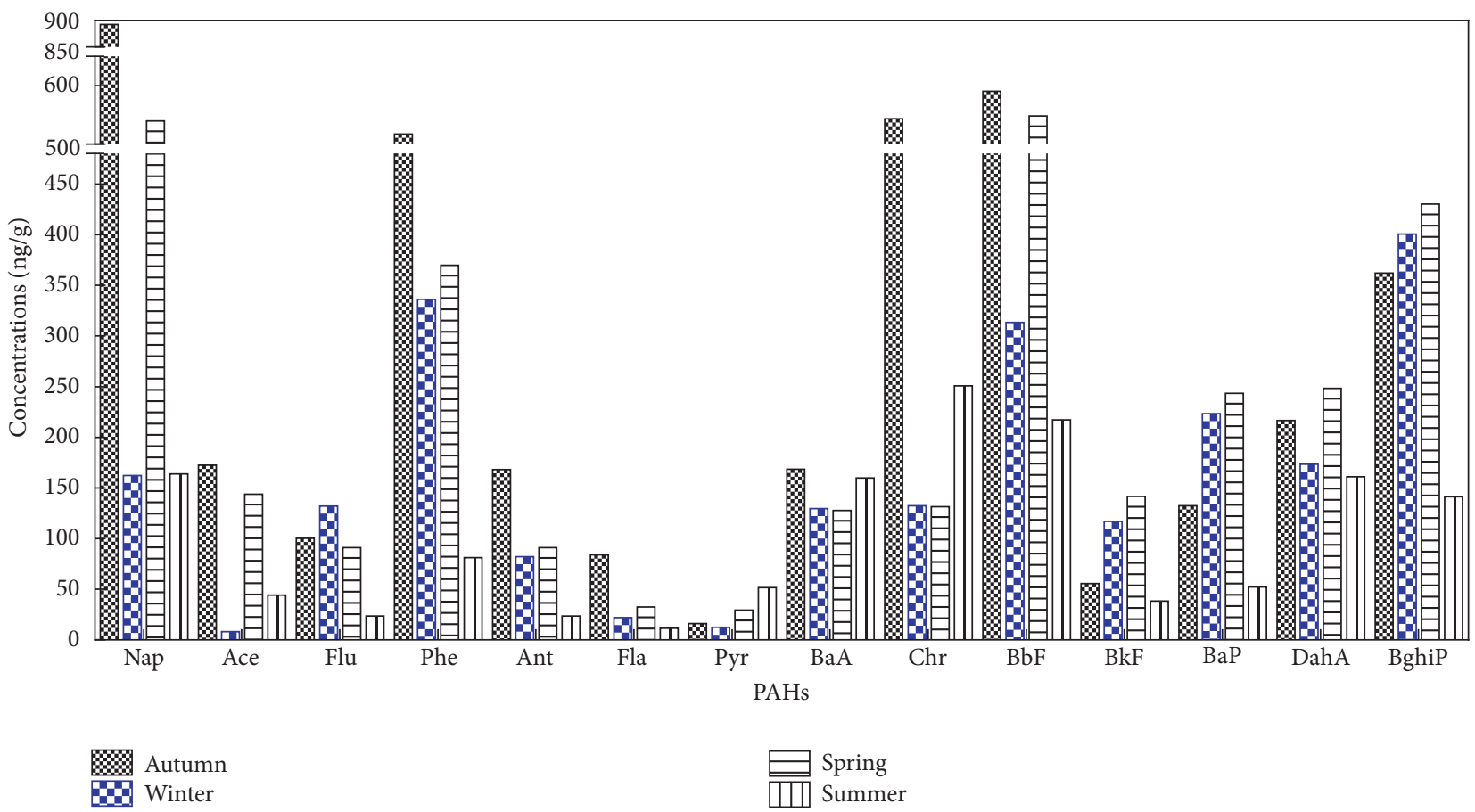

(c)

FIgURE 2: Temporal (b and c) and spatial variation (a) of $\sum$ PAHs in sediments.

3.1.2. Temporal and Spatial Variation of $\sum P A H s$ Compositions in Sediments. Figure 2(c) shows the seasonal average concentrations of 14 kinds of PAHs in sediments. Mean concentrations of 2-ring Nap, 3-ring Phe, and 5-ring BbF were very high during autumn and summer, while 4-ring Fla and Pyr were low during the four seasons. Overall, the PAHs with 3 and 5 rings were the dominant residual species in the spring and winter, and the concentrations of 3- and 5-ring PAHs were $59.25 \%$ and $61.73 \%$ of $\sum$ PAHs in spring and winter, respectively; the PAHs with 4 and 5 rings were the dominant residual species in summer, and the percentage contribution was $66.35 \%$, while in autumn they were 2-5 ring PAHs, accounting for $90.99 \%$. The concentration of high molecular weight PAHs ( $\sum$ HMWPAHs) showed lower variability than 
that of low molecular weight PAHs ( $\mathrm{L}$ LMWPAHs) along with the season change, because the higher solubility of LMWPAHs makes them easily enter the aquatic environment, more susceptible to be affected by the environmental conditions, such as long-distance transmission and evaporation. High temperatures and heavy rainfall in summer contributed to the conduct of this mechanism [39]. The HMWPAHs are relatively stable, are less affected by environmental conditions, and are not easily desorbed from sediments and degraded [50].

\subsection{Source Apportionment of the PAHs}

3.2.1. Source Estimates from Diagnostic Ratios. Diagnostic ratios are often employed to be accurate and reliable diagnostic tools for source identification of PAHs [51, 52]. As isomers of PAHs have similar thermodynamic and kinetic characteristics and isomers from the same source undergo the same migration process, their ratio can be used as the eigenvalues of the source. The composition and content of PAHs vary from different types and conditions of combustion, so the ratio of different PAHs can determine the type of pollution sources. The ratio of low molecular weight and high molecular weight PAHs $(\mathrm{L} / \mathrm{H})$ and isomers are commonly used as a ratio method. These groups of compounds had molecular weight of 178 (phenanthrene and anthracene), 202 (fluoranthene and pyrene), 228 (benzo[a] anthracene and chrysene), and 276 (indeno[1,2,3-cd]pyrene and benzo[g,h,i]perylene). In the present study, the ratios of Ant/(Ant + Phe), Fla/(Fla + $\mathrm{Pyr})$, and $\mathrm{BaA} /(\mathrm{BaA}+\mathrm{Chr})$ were used to identify the PAHs sources in sediment. Ant/(Ant + Phe) ratios of $>0.1$ are the indicator of pyrogenic origin of PAHs, while $<0.1$ ratios are petrogenic origin of PAHs [51]. Meanwhile, a Fla/(Fla + Pyr) $<0.4$ ratio indicates a petroleum source, a ratio between 0.4 and 0.5 indicates liquid fossil fuel combustion, and a ratio of $>0.50$ suggests the combustion of biomass and coal $[53,54]$. In addition, $\mathrm{BaA} /(\mathrm{BaA}+\mathrm{Chr})$ ratio is considered as a specific marker for coal combustion $[55,56]$. The petroleum source is demonstrated if the ratio of $\mathrm{BaA} /(\mathrm{BaA}+\mathrm{Chr})$ is lower than 0.20; a source from combustion coal, grass, and wood is shown if the ratio is higher than 0.35 ; and petroleum combustion (especially liquid fossil fuel and vehicle and crude oil spillage) is demonstrated if the ratio is between 0.20 and 0.35 [51]. For a more detailed analysis of sources, the diagnostic ratios of Ant/(Ant + Phe), Fla/(Fla + Pyr), and $\mathrm{BaA} /(\mathrm{BaA}+\mathrm{Chr})$ for the four seasons are plotted in Figure 3. As shown in Figure 3, the source of each site was significantly different in summer, while the other three seasons were relatively convergent and consistent. These characteristic ratios demonstrated the PAHs in sediments of Qinhuai River mainly originated from petroleum and combustion of biomass and coal in spring, autumn, and winter is attributed to anthropogenic activities like straw burning before rice cultivation and after harvest, automobiles, and heating in winter and spring. Sources of PAHs in summer were relatively more diverse. Among the sampling sites, M14 was typical petroleum source, M13 and M15 were mixed sources of petroleum source, biomass, coal combustion, and petroleum combustion, and, additionally, M1 and M3 were biomass and coal combustion. Other sampling sites had a mixed source from pyrogenic sources and petroleum sources.

3.2.2. Source Estimates from Cluster Analysis. Cluster analysis was performed to identify the homogeneous groups of individual PAHs in the Qinhuai River sediments. The result of cluster analysis is shown in the hierarchical dendrogram (Figure 4), which distinguishes the 14 individual PAHs into three major groups. The first group is subdivided into two subgroups. The first subgroup contains $\mathrm{BaP}, \mathrm{BkF}$, and BghiP, which are the high molecular weight PAHs with 56 rings, usually detected in pyrogenic sources, for example, combustion of biomass, coal, wood, and petroleum. The second subgroup consists of Flu and Phe, which are 3-ring PAHs, from petrogenic sources mainly caused by petroleum spills, for example, fresh or used crankcase oil, crude, and fuel oil [57-61]. The results indicate the first group is mixed pyrogenic sources and petroleum sources. The second major group, which includes Nap, Ace, Ant, and Fla belonging to the low molecular weight PAHs with 2-3 rings, is usually detected in petrogenic sources. The third major group contains $\mathrm{Pyr}$ and $\mathrm{Chr}$ with 4 rings and $\mathrm{BaA}, \mathrm{BbF}$, and $\mathrm{DahA}$ with 5 rings, the same as the first subgroup of the first group, usually detected in pyrogenic sources, for example, combustion of coal, wood, vehicle fuel, and waste tire $[56,62,63]$. The results of the second and third groups are consistent with the study by Liu et al. [12], which is attributed to the fact that both Qinhuai River and Huangpu River are urban rivers affected by anthropogenic activities (heating, cooking, and vehicles).

3.2.3. Source Estimates from Positive Matrix Factorization $(P M F)$. For further ascertaining the validity of PAHs sources, fifty-two (52) objects (samples) and fourteen (14) variables (PAHs) together with their uncertainties were used as the input data. Factor numbers ranging from three to eight were considered in order to choose the "optimal solution." "Robust" mode was adopted to simulate for eliminating the effect of individual extreme value [21, 30, 64-69]. Three factors were eventually chosen since it gave $Q$ (robust) value ranging from 21041.1 to 23360.0 , which converged. The slope and $r^{2}$ values indicated that the predicted and actual concentrations were well fitted and three factors could adequately explain the data based on the background of $\mathrm{PAH}$ sources in the sediment.

The source identification was based on the molecular markers in different sources of PAHs. As shown in Table 4 and Figures 5 and 6 , the first factor $\left(f_{1}\right)$ is responsible for $33.4 \%$ contribution rate, and it is heavily weighted in Ant, $\mathrm{BaA}, \mathrm{BbF}, \mathrm{BkF}, \mathrm{BaP}, \mathrm{DahA}$, and BghiP with 4-6 rings. Venkataraman et al. (1994) thought that BkF was typical pollutant of diesel emissions [70]. Ant, $\mathrm{BaA}, \mathrm{Chr}$, and $\mathrm{BaP}$ were thought to be typical pollutants of biomass or coal combustion $[71,72]$. Indeno[1,2,3-cd]pyrene (InP), BghiP, and DahA were typical markers of traffic emission $[73,74]$. Hence, this factor represents the traffic-related source > biomass and coal combustion of PAHs, which accounts for the larger proportion of all the sources; Nanjing has a large population and also many private cars and buses. Figure 7 


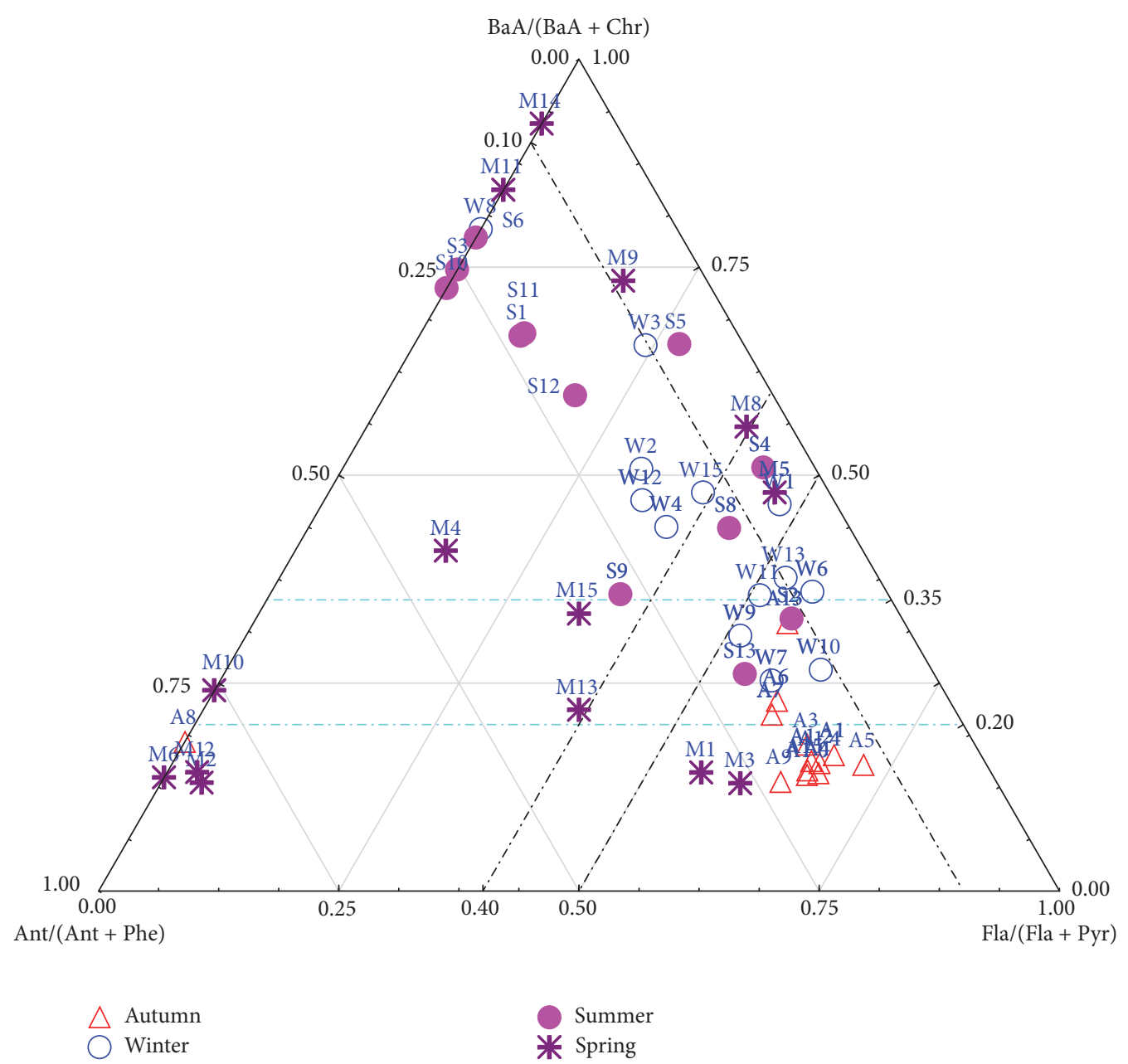

Figure 3: Plot of seasonal isomeric ratios Ant/(Ant + Phe) versus BaA/(BaA + Chr) versus Fla/(Fla + Pry). A: autumn, W: winter, S: spring, and $\mathrm{M}$ : summer.

illustrates the seasonal contributions of vehicular emission are spring $>$ winter $>$ autumn $>$ summer. The results are the same as those studied by Liu et al. [12], indicating the choice of transport is temperature-related and people tend to choose cars in cold seasons. Factor $2\left(f_{2}\right)$ is predominately composed of PAHs with 3-6 rings, including Flu, Phe, Pyr, $\mathrm{Chr}, \mathrm{BkF}, \mathrm{BaP}$, and BghiP, which mainly come from biomass and coal combustion [75]. Some researches showed that Phe, Ant, Fla, and Pyr were indicative of coal combustion [76]. According to Khalili et al., gasoline combustion was shown to predominantly produce Nap, Flu, Acy, and Pyr [77]. Meanwhile, BghiP and BkF have been identified as tracers for gasoline engines, with Pyr found in both diesel- and gasolinepowered engines [71]. And $\mathrm{BaA}, \mathrm{Chr}$, and $\mathrm{BaP}$ were thought to be typical pollutants of biomass and coal combustion [71]. Therefore, factor $2\left(f_{2}\right)$ suggests a mixed source of biomass and coal combustion equal to or $>$ diesel and gasoline combustion sources, which is responsible for $25.3 \%$ of the total contribution rate throughout the year. Figure 7 shows that winter has the biggest contribution from mixed sources, followed by spring, autumn, and summer. Because winter and spring temperature are relatively low, people will use coal combustion, air conditioners, and other electrical facilities for heating. Nanjing municipal electric power supply is mainly derived from coal-burning power plants. Assigning this factor to coal combustion is demonstrated and shows a seasonal variation. The third factor $\left(f_{3}\right)$ is predominately composed of Nap, Ace, Phe, Ant, Fla, and Chr with higher loadings. The higher level of Nap and Ace relative to other PAHs suggests a petroleum source [77]. Existing research showed that Ace and acenaphthylene (Acy) are the foremost product of coke burning [78]. And Phe, Ant, Fla, and Chr were indicative of coal combustion [71, 76]. Therefore, factor $3\left(f_{3}\right)$ was identified as petroleum source $>$ coal combustion $[79,80]$. Petroleum source and coal combustion are a major source in the Qinhuai River basin, contributing about 34.9\% of PAHs throughout the year. From Figure 7, we can see its seasonal contributions: autumn $>$ spring $>$ winter $>$ summer. Petroleum source may be related to the Yangzi Petrochemical Plant located in the main urban area of Nanjing city.

From above we can see that source characterization studies based on the analysis of diagnostic ratio (triangular plot method), cluster analysis, and positive factor matrix analysis [81] suggested that the PAHs of Qinhuai River Basin were 
TABLE 4: Factor profiles ( $F$ matrix) of individual PAHs in each of the three PMF factors identified in the analysis of Qinhuai River sediment data set.

\begin{tabular}{|c|c|c|c|}
\hline \multirow{2}{*}{ PAHs } & \multicolumn{3}{|c|}{ Factor profiles obtained from PMF (\% of species) } \\
\hline & Factor 1 & Factor 2 & Factor 3 \\
\hline Nap & 0.000 & 0.178 & 0.822 \\
\hline Ace & 0.013 & 0.000 & 0.987 \\
\hline Flu & 0.313 & 0.580 & 0.107 \\
\hline Phe & 0.106 & 0.567 & 0.327 \\
\hline Ant & 0.457 & 0.157 & 0.386 \\
\hline Fla & 0.055 & 0.076 & 0.869 \\
\hline Pyr & 0.000 & 1.000 & 0.000 \\
\hline $\mathrm{BaA}$ & 0.655 & 0.163 & 0.182 \\
\hline Chr & 0.043 & 0.333 & 0.625 \\
\hline $\mathrm{BbF}$ & 0.673 & 0.015 & 0.312 \\
\hline $\mathrm{BkF}$ & 0.493 & 0.500 & 0.007 \\
\hline $\mathrm{BaP}$ & 0.477 & 0.523 & 0.000 \\
\hline DahA & 0.845 & 0.000 & 0.155 \\
\hline BghiP & 0.547 & 0.353 & 0.100 \\
\hline $\begin{array}{l}\text { Estimated } \\
\text { source }\end{array}$ & $\begin{array}{l}\text { Traffic-related, biomass }> \\
\text { coal combustion }\end{array}$ & $\begin{array}{c}\text { Biomass and coal } \\
\text { combustion, }=\text { or }>\text { diesel } \\
\text { and gasoline combustion } \\
\text { sources }\end{array}$ & $\begin{array}{l}\text { Petroleum source }>\text { coal } \\
\text { combustion }\end{array}$ \\
\hline Rate (\%) & 33.4 & 25.3 & 34.9 \\
\hline
\end{tabular}

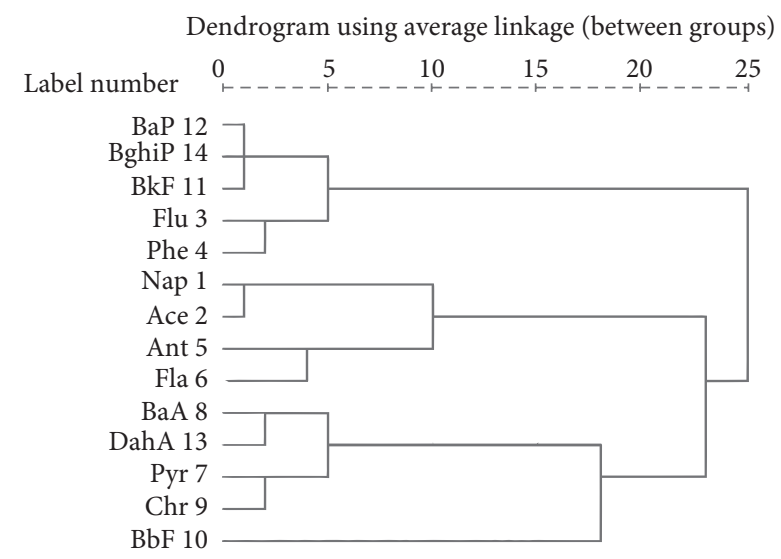

FIgURE 4: Hierarchical dendrogram for 14 PAHs in the Qinhuai River sediments using average linkage between groups and Pearson correlation as measure interval.

mainly from pyrogenic origin (biomass and coal combustion and vehicular emission), and the petroleum source also can not be ignored (specially in summer).

\subsection{Ecological Risk Assessments of PAHs in Surface Sediments}

3.3.1. Sediment Quality Guidelines (SQGs). PAHs often accumulate in various environmental systems including coastal estuaries and marine sediments [82]. Sediments release PAHs into water as an intrinsic source, which harms aquatic organisms, and then it is harmful to human health, so PAHs of sediments are a potential threat to aquatic ecosystems. Therefore, ecological risk assessment of PAHs in surface sediments from the city-river like Qinhuai River is very important to protect human health and for ecological environment security. The need for chemical guidelines that could be used to predict adverse biological effects in contaminated sediments led to the development of sediment quality guidelines (SQGs) during the last decade [83]. SQGs developed on the basis of Biological Effects Database for Sediments (BEDS) are very useful for sediment assessments in freshwater and marine environments. BEDS contain data that can be used to establish links between the concentration of a given chemical and its biological effect. One of the most widely applied SQGs for estuarine and marine stations is effects range-low (ERL) and effects range-median (ERM) [84]. Threshold effects levels (TELs) and probable effects levels (PELs) are also considered to be widely applicable [85]. These two sets of SQGs can be used to identify three ranges of chemical concentrations, including a low range, within which adverse biological effects are unlikely to occur: below the TEL or ERL values; a middle range, within which adverse biological effects are possible: between the TEL or ERL and PEL or ERM values; and an upper range, within which adverse biological effects are likely to occur: above the PEL or ERM values [42, 84, 85].

As shown in Tables 5 and 6, all the sampling sites are below ERL values except for 13\# and 9\# in spring. However, concentrations of Nap, Flu, Phe, Ant, and Chr in autumn; Flu and Phe in winter; Nap, Ace, Flu, Phe, Ant, and BaP in spring; and Nap in summer are all above the PEL values, indicating that these sampling sites are likely to have adverse 


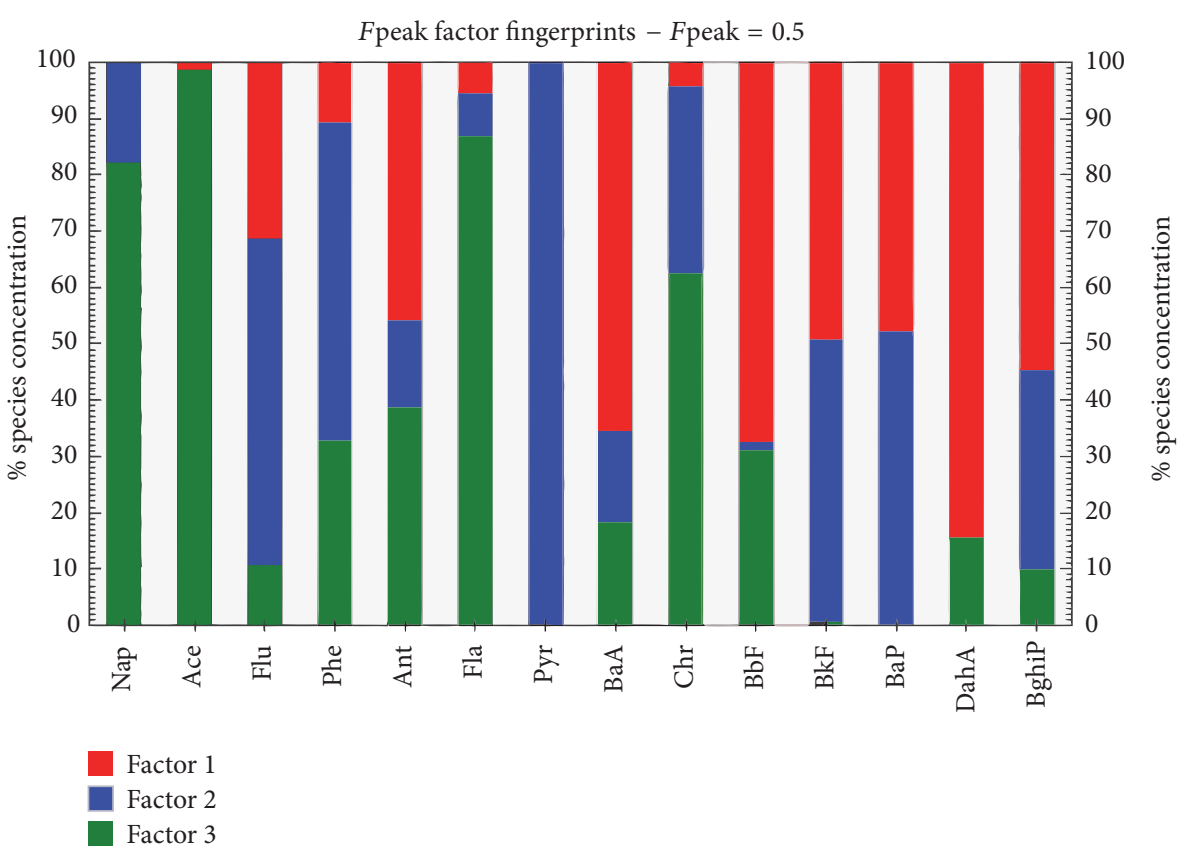

FIGURE 5: Factor fingerprints of three PMF factors in each of the individual PAHs.

biological effects on the environment, and the sequence is as follows: autumn $>$ spring $>$ winter $>$ summer. For $\sum$ PAHs, the concentrations in all sites are lower than corresponding PEL values. Relative percentages of sites are 23\%, 85\%, $67 \%$, and $86 \%$ in autumn, winter, spring, and summer, respectively, of which $\sum$ PAHs concentrations are below TEL values, suggesting that the adverse biological effects may be unlikely to occur. In this study, Low molecular weight PAHs (LMWPAHs) concentrations were in the intermediate range $(\geqslant E R L$ and $<E R M)$, indicating that occasionally adverse biological effects were likely to occur for LMWPAHs at most sites of Qinhuai River during four seasons, which is the same as that studied by Liu et al. [83]. Concentrations levels of high molecular weight PAHs (HMWPAHs) except for Fla and Pyr were in the intermediate range ( $\geqslant$ TEL and $<\mathrm{PEL})$ in most sites, indicating that occasionally adverse biological effects were likely to occur for HMWPAHs. Additionally, there are no corresponding ERL/ERM or TEL/PEL values for BbF, BkF, DahA, and BghiP, showing there will be adverse biological effects on aquatic organisms as long as these four PAHs exist. These four PAHs were all detected at every sampling site of Qinhuai River in four seasons, showing they are a threat to the environment.

\subsubsection{Sediment Potential Human Toxicity and Biological} Effects Based on PAHs. Many PAHs, especially their degradation products, are carcinogenic, while benzo[a]pyrene is the only PAH with sufficient toxicological data for derivation of a carcinogenic potency factor [86]. Therefore, the toxic equivalency factor (TEF) was used to quantify the carcinogenicity of other PAHs relative to benzo[a]pyrene. In the present study, the potential toxicity of sediment was evaluated using the total toxic benzo[a]pyrene equivalent (TEQ) of five PAHs and calculated using the following equation:

$$
\mathrm{TEQ}=\sum\left(C_{i} \times \mathrm{TEF}_{i}\right),
$$

where $C_{i}$ is the concentration of the PAH congener and $\mathrm{TEF}_{i}$ is the toxic equivalency factor. According to US EPA [87], TEFs of $\mathrm{BaA}, \mathrm{BbF}, \mathrm{BkF}, \mathrm{BaP}$, and $\mathrm{Chr}$ are 0.1, 0.1, 0.1, 1 , and 0.001 , respectively [88]. Total TEQ values calculated for samples varied from 54.6 (site 13\#) to 558.6 (site 7\#) $\mathrm{ng} \mathrm{TEQ} \bullet \mathrm{g}^{-1}$ with an average of $214.3 \mathrm{ng} \mathrm{TEQ} \bullet \mathrm{g}^{-1}$ in autumn, 86.7 (station 8\#) to 600.4 (station 7\#) ng TEQ $\bullet \mathrm{g}^{-1}$, an average of $279.6 \mathrm{ng} \mathrm{TEQ} \cdot \mathrm{g}^{-1}$ in winter, 48.6 (site 13\#) to 583.0 (site $4 \#$ ) ng TEQ $\bullet \mathrm{g}^{-1}$, an average of $235.1 \mathrm{ng} \mathrm{TEQ} \mathrm{g}^{-1}$ in spring, and 22.1 (site 14\#) to 188.2 (site $1 \#)$ ng TEQ ${ }^{-1}{ }^{-1}$, with an average of $94.1 \mathrm{ng}$ TEQ $\bullet \mathrm{g}^{-1}$. Seasonal mean TEQ values ranged winter > spring $>$ autumn $>$ summer. The results showed that winter had largest impact on the ecological health and the maximum potential toxicity. This is probably due to people's choice of cars for travelling because of low temperatures and incomplete combustion of fossil fuels. The maximum TEQ value was found at site 7\# (Yunliang River) which received the tail water of sewage treatment plant, during autumn and winter. Therefore, direct sewage pollution was the main reason for the distribution of PAHs during autumn and winter in this study. It is reasonable to find that the maximum TEQ value in spring was at site $4 \#$, which received incoming water from eastern section of Internal Qinhuai River, where there are much vehicle traffic and domestic sewage. The maximum TEQ value was found at site $1 \#$ in summer; this is attributed to the fact that site $1 \#$ is on the main roadside of Nanjing with constant heavy traffic, indicating that the distribution of PAHs of site $1 \#$ was affected by traffic. Therefore, we can 

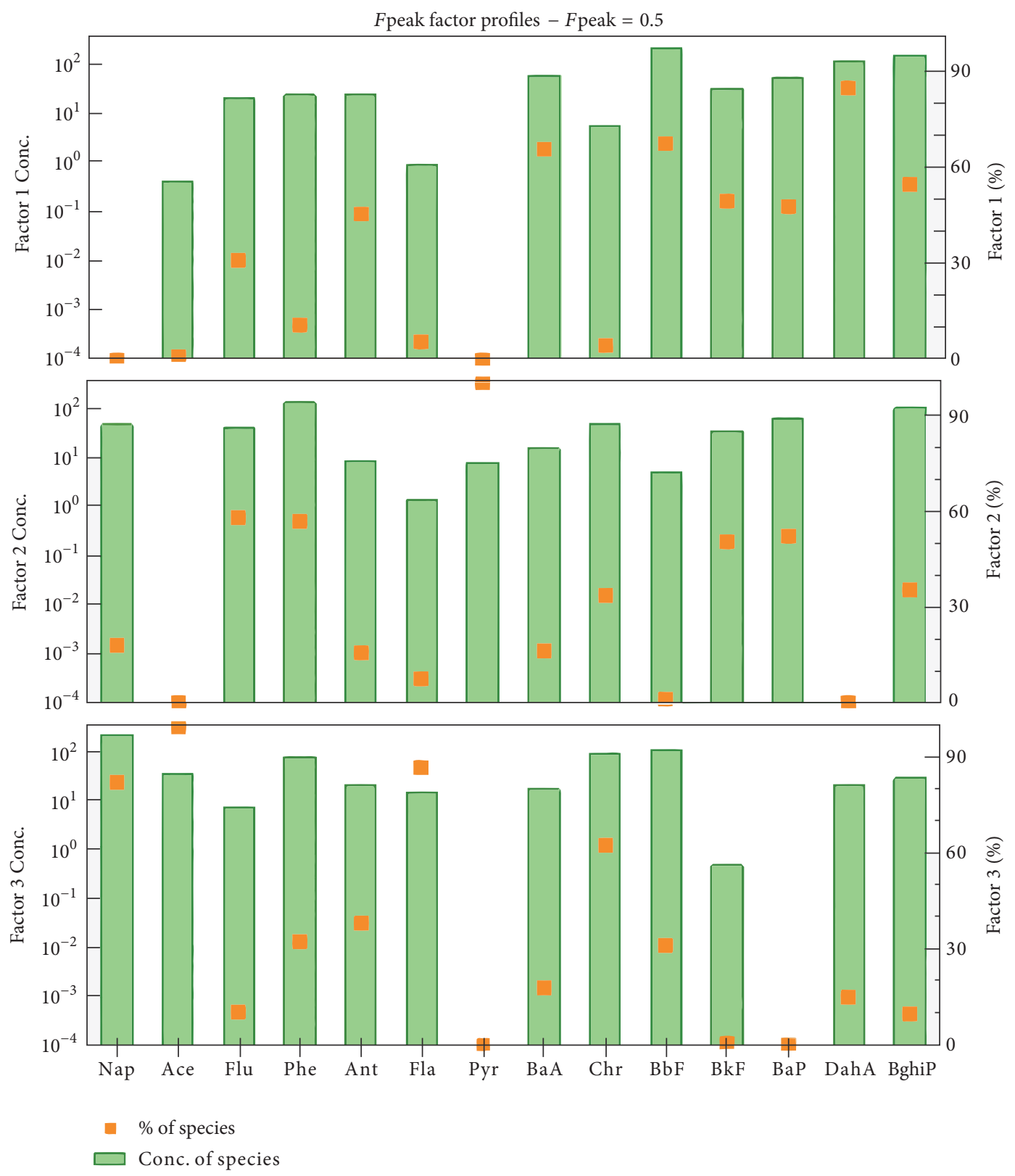

FIGURE 6: Concentrations and percentage of individual PAHs in each of the three PMF factors.

analyze potential toxicity and ecological effects of the Qinhuai River in different seasons based on the TEQ value and then develop mitigation options based on the results.

\section{Conclusions}

In this study, we chose 15 typical sites in the Qinhuai River and Xuanwu Lake during four seasons. The distribution, sources, and risk assessment of PAHs in sediment are studied using different methods. The comparisons of different methods (diagnostic ratio, cluster analysis, and positive factor matrix analysis) for source analysis confirmed the PAHs of Qinhuai River are primarily from pyrogenic origin (biomass and coal combustion and vehicular emission), and the petroleum source also can not be ignored (specially in summer), and the
PAHs pollution sources of urban water body have obvious seasonal-dependent and human activities-dependent characteristics. The result of ecological risk assessment shows the highest benzo[a]pyrene-equivalent dose $\left(\mathrm{BaP}_{\mathrm{eq}}\right.$ dose) appears at the sites of sewage discharge and heavy traffic, which should be the focus of continued study.

\section{Conflicts of Interest}

The authors declare that they have no conflicts of interest.

\section{Acknowledgments}

This work was supported by National Natural Science Foundation of China (41230640, 41371307, and 51509129), 


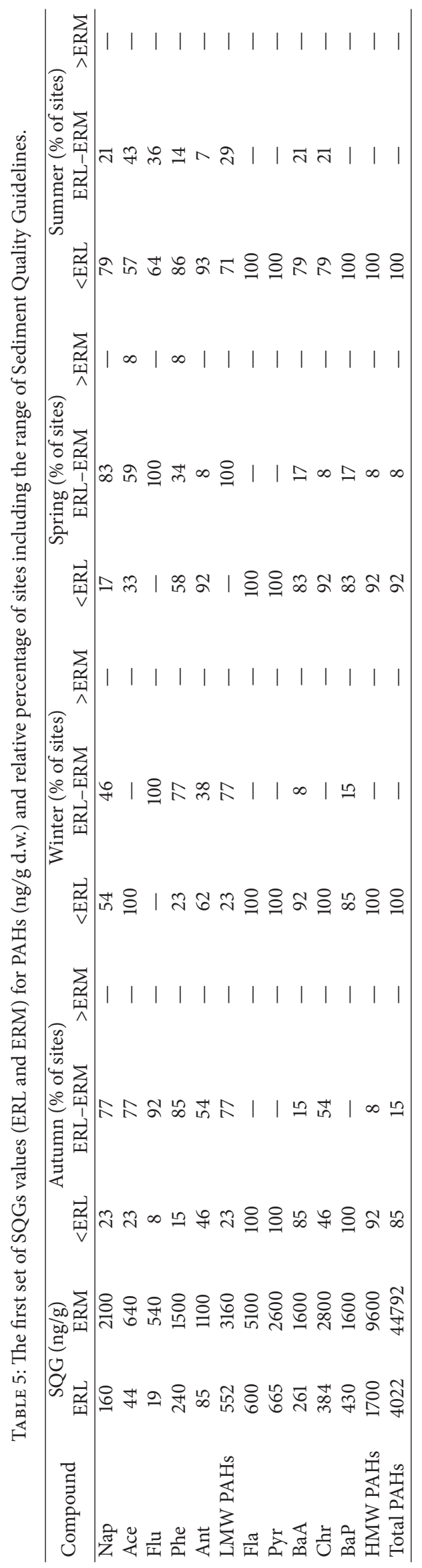




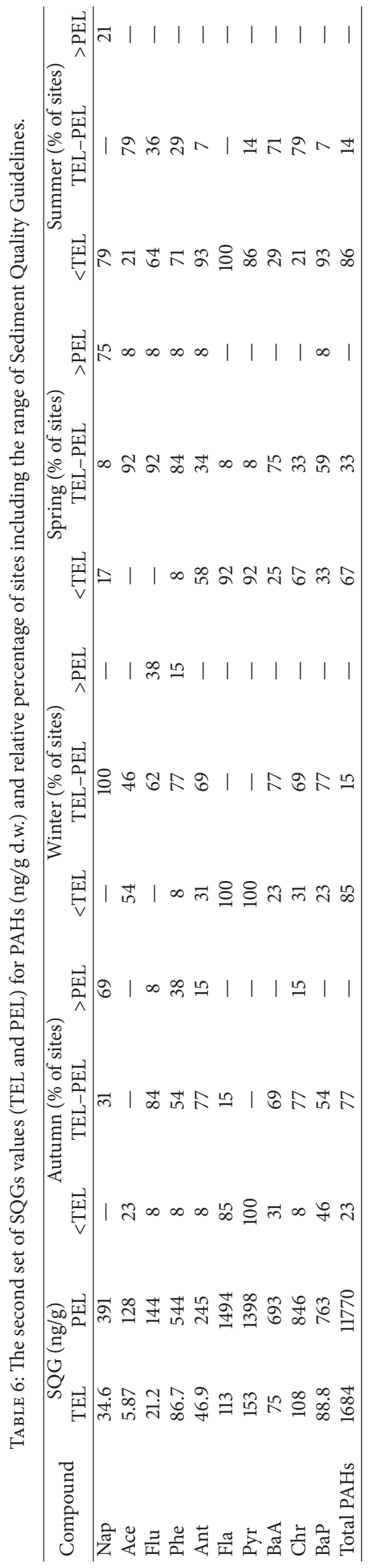




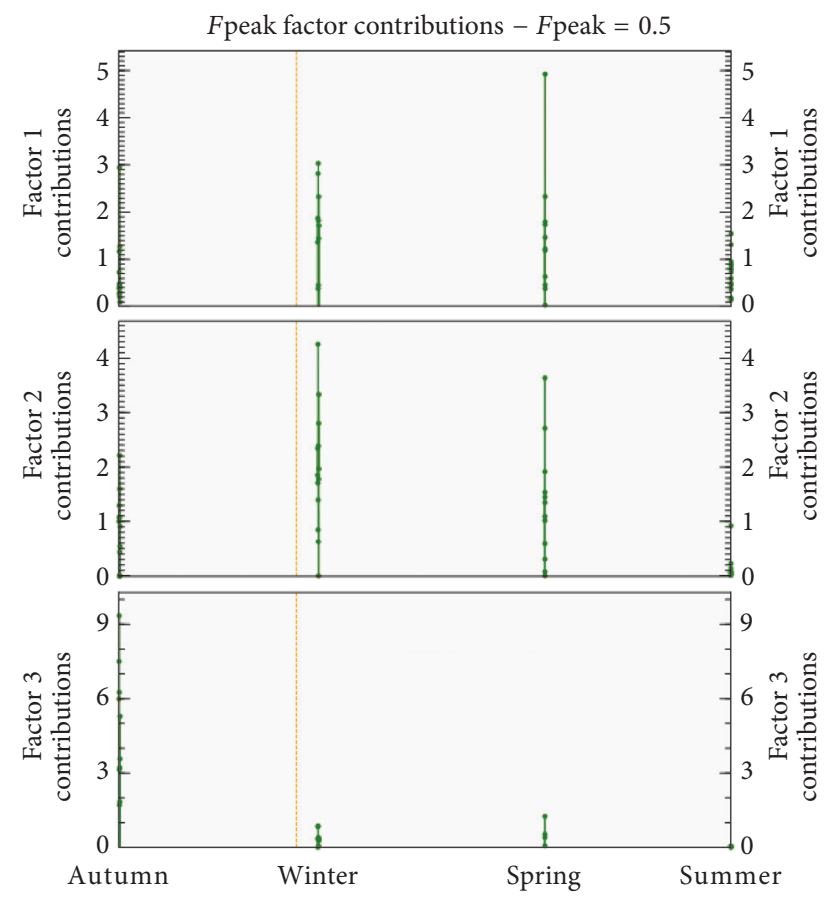

FIgURE 7: Seasonal contributions of PMF factor profiles.

Natural Science Foundation of Jiangsu Province, China (BK20171435), the Opening Funding of State Key Laboratory of Pollution Control and Resource Reuse (PCRRF12010), the State Key Laboratory of Soil and Sustainable Agriculture, Institute of Soil Science, Chinese Academy of Sciences Foundation (0812201228), and a project funded by the Priority Academic Program Development of Jiangsu Higher Education Institutions (PAPD) and TAPP. Thanks are due to Professor Mark who worked in Michigan State University for the English language revision.

\section{References}

[1] G. Li, X. Xia, Z. Yang, R. Wang, and N. Voulvoulis, "Distribution and sources of polycyclic aromatic hydrocarbons in the middle and lower reaches of the Yellow River, China," Environmental Pollution, vol. 144, no. 3, pp. 985-993, 2006.

[2] N. Hu, X. Shi, P. Huang et al., "Polycyclic aromatic hydrocarbons (PAHs) in surface sediments of Liaodong Bay, Bohai Sea, China," Environmental Science and Pollution Research, vol. 18, no. 2, pp. 163-172, 2011.

[3] N. Hu, X. Shi, J. Liu, P. Huang, Y. Liu, and Y. Liu, "Concentrations and possible sources of PAHs in sediments from Bohai Bay and adjacent shelf," Environmental Earth Sciences, vol. 60, no. 8, pp. 1771-1782, 2010.

[4] J. Liang, G. Ma, H. Fang, L. Chen, and P. Christie, "Polycyclic aromatic hydrocarbon concentrations in urban soils representing different land use categories in Shanghai," Environmental Earth Sciences, vol. 62, no. 1, pp. 33-42, 2011.

[5] A. C. Ruiz-Fernández, M. Sprovieri, M. Frignani et al., "Reconstruction of hydrocarbons accumulation in sediments affected by the oil refinery industry: The case of Tehuantepec Gulf
(Mexico)," Environmental Earth Sciences, vol. 67, no. 3, pp. 727742,2012

[6] P. Gong, X. Wang, and T. Yao, "Ambient distribution of particulate- and gas-phase n-alkanes and polycyclic aromatic hydrocarbons in the Tibetan Plateau," Environmental Earth Sciences, vol. 64, no. 7, pp. 1703-1711, 2011.

[7] Z. Wang, J. Chen, P. Yang, X. Qiao, and F. Tian, "Polycyclic aromatic hydrocarbons in Dalian soils: distribution and toxicity assessment," J. Environ. Monit., vol. 9, no. 2, pp. 199-204, 2007.

[8] K. L. White, "An overview of immunotoxicology and carcinogenic polycyclic aromatic hydrocarbons," Environmental Carcinogenesis Reviews, vol. 4, no. 2, pp. 163-202, 1986.

[9] P. Baumard, H. Budzinski, and P. Garrigues, "Polycyclic aromatic hydrocarbons in sediments and mussels of the Western Mediterranean Sea," Environmental Toxicology and Chemistry, vol. 17, no. 5, pp. 765-776, 1998.

[10] D. Broman, C. Näf, C. Rolff, and Y. Zebühr, "Occurrence and dynamics of polychlorinated dibenzo-p-dioxins and dibenzofurans and polycyclic aromatic hydrocarbons in the mixed surface layer of remote coastal and offshore waters of the Baltic," Environmental Science \& Technology, vol. 25, no. 11, pp. 18501864,1991

[11] K. Naes and E. Oug, "Multivariate approach to distribution patterns and fate of polycyclic aromatic hydrocarbons in sediments from smelter-affected Norwegian fjords and coastal waters," Environmental Science \& Technology, vol. 31, no. 5, pp. 12531258, 1997.

[12] Y. Liu, L. Chen, Q. Huang, W. Li, Y. Tang, and J. Zhao, "Source apportionment of polycyclic aromatic hydrocarbons (PAHs) in surface sediments of the Huangpu River, Shanghai, China," Science of the Total Environment, vol. 407, no. 8, pp. 2931-2938, 2009.

[13] O. P. Heemken, B. Stachel, N. Theobald, and B. W. Wenclawiak, "Temporal variability of organic micropollutants in suspended particulate matter of the River Elbe at Hamburg and the River Mulde at Dessau, Germany," Archives of Environmental Contamination and Toxicology, vol. 38, no. 1, pp. 11-31, 2000.

[14] F. G. Prahl and R. Carpenter, "The role of zooplankton fecal pellets in the sedimentation of polycyclic aromatic hydrocarbons in Dabob Bay, Washington," Geochimica et Cosmochimica Acta, vol. 43, no. 12, pp. 1959-1972, 1979.

[15] L. Guzzella and A. De Paolis, "Polycyclic aromatic hydrocarbons in sediments of the Adriatic Sea," Marine Pollution Bulletin, vol. 28, no. 3, pp. 159-165, 1994.

[16] M. Lu, D.-C. Zeng, Y. Liao, and B. Tong, "Distribution and characterization of organochlorine pesticides and polycyclic aromatic hydrocarbons in surface sediment from Poyang Lake, China," Science of the Total Environment, vol. 433, pp. 491-497, 2012.

[17] H.-S. Wang, Z. Cheng, P. Liang et al., "Characterization of PAHs in surface sediments of aquaculture farms around the Pearl River Delta," Ecotoxicology and Environmental Safety, vol. 73, no. 5, pp. 900-906, 2010.

[18] X. He, Y. Pang, X. Song, B. Chen, Z. Feng, and Y. Ma, "Distribution, sources and ecological risk assessment of PAHs in surface sediments from Guan River Estuary, China," Marine Pollution Bulletin, vol. 80, no. 1-2, pp. 52-58, 2014.

[19] N.-J. Hu, P. Huang, J.-H. Liu et al., "Characterization and source apportionment of polycyclic aromatic hydrocarbons (PAHs) in sediments in the Yellow River Estuary, China," Environmental Earth Sciences, vol. 71, no. 2, pp. 873-883, 2014. 
[20] B. Li, C. Feng, X. Li, Y. Chen, J. Niu, and Z. Shen, "Spatial distribution and source apportionment of PAHs in surficial sediments of the Yangtze Estuary, China," Marine Pollution Bulletin, vol. 64, no. 3, pp. 636-643, 2012.

[21] Y. Zhang, C.-S. Guo, J. Xu, Y.-Z. Tian, G.-L. Shi, and Y.-C. Feng, "Potential source contributions and risk assessment of PAHs in sediments from Taihu Lake, China: comparison of three receptor models," Water Research, vol. 46, no. 9, pp. 3065-3073, 2012.

[22] Z. Zhang, J. Huang, G. Yu, and H. Hong, "Occurrence of PAHs, PCBs and organochlorine pesticides in the Tonghui River of Beijing, China," Environmental Pollution, vol. 130, no. 2, pp. 249-261, 2004.

[23] X. Zhao, J. Ding, and H. You, "Spatial distribution and temporal trends of polycyclic aromatic hydrocarbons (PAHs) in water and sediment from Songhua River, China," Environmental Geochemistry and Health, vol. 36, no. 1, pp. 131-143, 2014.

[24] Y. Liu, L. Chen, Z. Jianfu, H. Qinghui, Z. Zhiliang, and G. Hongwen, "Distribution and sources of polycyclic aromatic hydrocarbons in surface sediments of rivers and an estuary in Shanghai, China," Environmental Pollution, vol. 154, no. 2, pp. 298-305, 2008.

[25] W.-L. Ma, L.-Y. Liu, H. Qi et al., "Polycyclic aromatic hydrocarbons in water, sediment and soil of the Songhua River Basin, China," Environmental Modeling \& Assessment, vol. 185, no. 10, pp. 8399-8409, 2013.

[26] U. M. Sofowote, B. E. Mccarry, and C. H. Marvin, "Source apportionment of PAH in Hamilton Harbour suspended sediments: Comparison of two factor analysis methods," Environmental Science \& Technology, vol. 42, no. 16, pp. 6007-6014, 2008.

[27] C. Feng, X. Xia, Z. Shen, and Z. Zhou, "Distribution and sources of polycyclic aromatic hydrocarbons in Wuhan section of the Yangtze River, China," Environmental Modeling \& Assessment, vol. 133, no. 1-3, pp. 447-458, 2007.

[28] Y. Chen, L. Zhu, and R. Zhou, "Characterization and distribution of polycyclic aromatic hydrocarbon in surface water and sediment from Qiantang River, China," Journal of Hazardous Materials, vol. 141, no. 1, pp. 148-155, 2007.

[29] Q. Chen, J. Liu, F. Liu, B. Wang, and Z. Cao, "Biologic risk and source diagnose of 16 PAHs from Haihe River Basin, China," Frontiers of Environmental Science \& Engineering, vol. 10, no. 1, pp. 46-52, 2016.

[30] P. Paatero and U. Tapper, "Positive matrix factorization: a nonnegative factor model with optimal utilization of error estimates of data values," Environmetrics, vol. 5, no. 2, pp. 111-126, 1994.

[31] P. Paatero, "Least squares formulation of robust non-negative factor analysis," Chemometrics and Intelligent Laboratory Systems, vol. 37, no. 1, pp. 23-35, 1997.

[32] P. Paatero, "The multilinear engine-a table-driven, least squares program for solving multilinear problems, including the $n$-way parallel factor analysis model," Journal of Computational and Graphical Statistics, vol. 8, no. 4, pp. 854-888, 1999.

[33] A. Reff, S. I. Eberly, and P. V. Bhave, "Receptor modeling of ambient particulate matter data using positive matrix factorization: review of existing methods," Journal of the Air \& Waste Management Association, vol. 57, no. 2, pp. 146-154, 2007.

[34] L. Zhao, H. Hou, Y. Shangguan et al., "Occurrence, sources, and potential human health risks of polycyclic aromatic hydrocarbons in agricultural soils of the coal production area surrounding Xinzhou, China," Ecotoxicology and Environmental Safety, vol. 108, pp. 120-128, 2014.
[35] O. E. Oyo-Ita, J. O. Offem, B. O. Ekpo, and P. A. Adie, "Anthropogenic PAHs in mangrove sediments of the Calabar River, SE Niger Delta, Nigeria," Applied Geochemistry, vol. 28, pp. 212-219, 2013.

[36] B. Jiang, H.-L. Zheng, G.-Q. Huang et al., "Characterization and distribution of polycyclic aromatic hydrocarbon in sediments of Haihe River, Tianjin, China," Journal of Environmental Sciences, vol. 19, no. 3, pp. 306-311, 2007.

[37] F. Liu, J. Liu, Q. Chen, B. Wang, and Z. Cao, "Pollution characteristics, ecological risk and sources of polycyclic aromatic hydrocarbons (PAHs) in surface sediment from Tuhai-Majia River system, China," Procedia Environmental Sciences, vol. 13, pp. 1301-1314, 2012.

[38] Y. Li, N. Song, Y. Yu, Z. Yang, and Z. Shen, "Characteristics of PAHs in street dust of Beijing and the annual wash-off load using an improved load calculation method," Science of the Total Environment, vol. 581-582, pp. 328-336, 2017.

[39] K. Hussain and R. R. Hoque, "Seasonal attributes of urban soil PAHs of the Brahmaputra Valley," Chemosphere, vol. 119, pp. 794-802, 2015.

[40] F. Kanzari, A. D. Syakti, L. Asia et al., "Aliphatic hydrocarbons, polycyclic aromatic hydrocarbons, polychlorinated biphenyls, organochlorine, and organophosphorous pesticides in surface sediments from the Arc river and the Berre lagoon, France," Environmental Science and Pollution Research, vol. 19, no. 2, pp. 559-576, 2012.

[41] G. Karaca and Y. Tasdemir, “Temporal and spatial variations in PAH concentrations in the sediment from the Nilufer Creek in Bursa, Turkey," Journal of Environmental Science and Health, Part A: Toxic/Hazardous Substances and Environmental Engineering, vol. 49, no. 8, pp. 900-912, 2014.

[42] Z. Cao, J. Liu, Y. Luan et al., "Distribution and ecosystem risk assessment of polycyclic aromatic hydrocarbons in the Luan River, China," Ecotoxicology, vol. 19, no. 5, pp. 827-837, 2010.

[43] S. E. Mcgroddy and J. W. Farrington, "Sediment porewater partitioning of polycyclic aromatic hydrocarbons in three cores from Boston Harbor, Massachusetts," Environmental Science \& Technology, vol. 29, no. 6, pp. 1542-1550, 1995.

[44] M. Keshavarzifard, M. P. Zakaria, and R. Sharifi, "Ecotoxicological and Health Risk Assessment of Polycyclic Aromatic Hydrocarbons (PAHs) in Short-Neck Clam (Paphia undulata) and Contaminated Sediments in Malacca Strait, Malaysia," Archives of Environmental Contamination and Toxicology, vol. 73, no. 3, pp. 474-487, 2017.

[45] M. M. Ahmed, P. Doumenq, M. O. Awaleh, A. D. Syakti, L. Asia, and S. Chiron, "Levels and sources of heavy metals and PAHs in sediment of Djibouti-city (Republic of Djibouti)," Marine Pollution Bulletin, vol. 120, no. 1-2, pp. 340-346, 2017.

[46] M. Potapova, N. Desianti, and M. Enache, "Potential effects of sediment contaminants on diatom assemblages in coastal lagoons of New Jersey and New York States," Marine Pollution Bulletin, vol. 107, no. 2, pp. 453-458, 2016.

[47] N. Z. M. Muslim, S. H. Babaheidari, and M. P. Zakaria, "Comparison of polycyclic aromatic hydrocarbons level between suspended solid and sediment samples of Pengkalan Chepa River, Kelantan state, Malaysia," in Proceedings of the 5th International Conference on Mathematics and Natural Sciences, ICMNS 2014, idn, November 2014.

[48] G. F. Birch, "Assessment of human-induced change and biological risk posed by contaminants in estuarine/harbour sediments: Sydney Harbour/estuary (Australia)," Marine Pollution Bulletin, vol. 116, no. 1-2, pp. 234-248, 2017. 
[49] J. L. Zhou and K. Maskaoui, "Distribution of polycyclic aromatic hydrocarbons in water and surface sediments from Daya Bay, China," Environmental Pollution, vol. 121, no. 2, pp. 269-281, 2003.

[50] Z. Shi, S. Tao, B. Pan et al., "Contamination of rivers in Tianjin, China by polycyclic aromatic hydrocarbons," Environmental Pollution, vol. 134, no. 1, pp. 97-111, 2005.

[51] M. B. Yunker, R. W. Macdonald, R. Vingarzan, R. H. Mitchell, D. Goyette, and S. Sylvestre, "PAHs in the Fraser River basin: a critical appraisal of PAH ratios as indicators of PAH source and composition," Organic Geochemistry, vol. 33, no. 4, pp. 489-515, 2002.

[52] H. B. Zhang, Y. M. Luo, M. H. Wong, Q. G. Zhao, and G. L. Zhang, "Distributions and Concentrations of PAHs in Hong Kong Soils," Environmental Pollution, vol. 141, no. 1, pp. 107-114, 2006.

[53] H. Budzinski, O. Mazéas, J. Tronczynski, Y. Désaunay, G. Bocquené, and G. Claireaux, "Link between exposure of fish (Solea solea) to PAHs and metabolites: Application to the "Erika" oil spill," Aquatic Living Resources, vol. 17, no. 3, pp. 329334, 2004.

[54] C. Wang, W. Wang, S. He, J. Du, and Z. Sun, "Sources and distribution of aliphatic and polycyclic aromatic hydrocarbons in Yellow River Delta Nature Reserve, China," Applied Geochemistry, vol. 26, no. 8, pp. 1330-1336, 2011.

[55] M. Saha, A. Togo, K. Mizukawa et al., "Sources of sedimentary PAHs in tropical Asian waters: differentiation between pyrogenic and petrogenic sources by alkyl homolog abundance," Marine Pollution Bulletin, vol. 58, no. 2, pp. 189-200, 2009.

[56] M. P. Zakaria, H. Takada, S. Tsutsumi et al., "Distribution of polycyclic aromatic hydrocarbons (PAHs) in rivers and estuaries in Malaysia: a widespread input of petrogenic PAHs," Environmental Science \& Technology, vol. 36, no. 9, pp. 19071918, 2002.

[57] Y. Bixiong, Z. Zhihuan, and M. Ting, "Pollution sources identification of polycyclic aromatic hydrocarbons of soils in Tianjin area, China," Chemosphere, vol. 64, no. 4, pp. 525-534, 2006.

[58] R. A. Dobbins, R. A. Fletcher, B. A. Benner Jr., and S. Hoeft, "Polycyclic aromatic hydrocarbons in flames, in diesel fuels, and in diesel emissions," Combustion and Flame, vol. 144, no. 4, pp. 773-781, 2006.

[59] T. I. R. Utvik, G. S. Durell, and S. Johnsen, "Determining produced water originating polycyclic aromatic hydrocarbons in North Sea waters: Comparison of sampling techniques," Marine Pollution Bulletin, vol. 38, no. 11, pp. 977-989, 1999.

[60] J. J. González, L. Viñas, M. A. Franco et al., "Spatial and temporal distribution of dissolved/dispersed aromatic hydrocarbons in seawater in the area affected by the Prestige oil spill," Marine Pollution Bulletin, vol. 53, no. 5-7, pp. 250-259, 2006.

[61] L. C. Marr, T. W. Kirchstetter, R. A. Harley, A. H. Miguel, S. V. Hering, and S. K. Hammond, "Characterization of polycyclic aromatic hydrocarbons in motor vehicle fuels and exhaust emissions," Environmental Science \& Technology, vol. 33, no. 18, pp. 3091-3099, 1999.

[62] Y. A. Levendis, A. Atal, and J. B. Carlson, "On the correlation of $\mathrm{CO}$ and $\mathrm{PAH}$ emissions from the combustion of pulverized coal and waste tires," Environmental Science \& Technology, vol. 32, no. 23, pp. 3767-3777, 1998.

[63] Z. Wang, K. Li, P. Lambert, and C. Yang, "Identification, characterization and quantitation of pyrogenic polycylic aromatic hydrocarbons and other organic compounds in tire fire products," Journal of Chromatography A, vol. 1139, no. 1, pp. 1426, 2007.

[64] Y.-H. Lang, G.-L. Li, X.-M. Wang, P. Peng, and J. Bai, “Combination of Unmix and positive matrix factorization model identifying contributions to carcinogenicity and mutagenicity for polycyclic aromatic hydrocarbons sources in Liaohe delta reed wetland soils, China," Chemosphere, vol. 120, pp. 431-437, 2015.

[65] Y. Zou, L. Wang, and E. R. Christensen, "Problems in the fingerprints based polycyclic aromatic hydrocarbons source apportionment analysis and a practical solution," Environmental Pollution, vol. 205, article no. 7968, pp. 394-402, 2015.

[66] J. Xu, X. Peng, C.-S. Guo et al., "Sediment PAH source apportionment in the Liaohe River using the ME2 approach: A comparison to the PMF model," Science of the Total Environment, vol. 553, pp. 164-171, 2016.

[67] G. O. Duodu, K. N. Ogogo, S. Mummullage, F. Harden, A. Goonetilleke, and G. A. Ayoko, "Source apportionment and risk assessment of PAHs in Brisbane River sediment, Australia," Ecological Indicators, vol. 73, pp. 784-799, 2017.

[68] W. Yu, R. Liu, J. Wang, F. Xu, and Z. Shen, "Source apportionment of PAHs in surface sediments using positive matrix factorization combined with GIS for the estuarine area of the Yangtze River, China," Chemosphere, vol. 134, pp. 263-271, 2015.

[69] L. Hu, X. Shi, S. Qiao, Y. Bai, B. Wu, and S. Liu, "Sources and mass inventory of sedimentary polycyclic aromatic hydrocarbons in the Gulf of Thailand: Implications for pathways and energy structure in SE Asia," Science of the Total Environment, vol. 575, pp. 982-995, 2017.

[70] C. Venkataraman, J. M. Lyons, and S. K. Friedlander, "Size distributions of polycyclic aromatic hydrocarbons and elemental carbon. 1. Sampling, measurement methods, and source characterization," Environmental Science \& Technology, vol. 28, no. 4, pp. 555-562, 1994.

[71] R. K. Larsen III and J. E. Baker, "Source apportionment of polycyclic aromatic hydrocarbons in the urban atmosphere: a comparison of three methods," Environmental Science \& Technology, vol. 37, no. 9, pp. 1873-1881, 2003.

[72] Y. Chen, G. Sheng, X. Bi, Y. Feng, B. Mai, and J. Fu, “Emission factors for carbonaceous particles and polycyclic aromatic hydrocarbons from residential coal combustion in China," Environmental Science \& Technology, vol. 39, no. 6, pp. 18611867, 2005.

[73] S. Liu, X. Liu, M. Liu et al., "Levels, sources and risk assessment of PAHs in multi-phases from urbanized river network system in Shanghai," Environmental Pollution, vol. 219, pp. 555-567, 2016.

[74] T. T. T. Dong and B.-K. Lee, "Characteristics, toxicity, and source apportionment of polycylic aromatic hydrocarbons (PAHs) in road dust of Ulsan, Korea," Chemosphere, vol. 74, no. 9, pp. 12451253, 2009.

[75] B. M. Jenkins, A. D. Jones, S. Q. Turn, and R. B. Williams, "Emission factors for polycyclic aromatic hydrocarbons from biomass burning," Environmental Science \& Technology, vol. 30, no. 8, pp. 2462-2469, 1996.

[76] Y. Yu, Y. Yang, M. Liu et al., "PAHs in organic film on glass window surfaces from central Shanghai, China: Distribution, sources and risk assessment," Environmental Geochemistry and Health, vol. 36, no. 4, pp. 665-675, 2014. 
[77] N. R. Khalili, P. A. Scheff, and T. M. Holsen, "PAH source fingerprints for coke ovens, diesel and gasoline engines, highway tunnels, and wood combustion emissions," Atmospheric Environment, vol. 29, no. 4, pp. 533-542, 1995.

[78] M. F. Simcik, S. J. Eisenreich, and P. J. Lioy, "Source apportionment and source/sink relationships of PAHs in the coastal atmosphere of Chicago and Lake Michigan," Atmospheric Environment, vol. 33, no. 30, pp. 5071-5079, 1999.

[79] M. Zheng, L. G. Salmon, J. J. Schauer et al., "Seasonal trends in PM2.5 source contributions in Beijing, China," Atmospheric Environment, vol. 39, no. 22, pp. 3967-3976, 2005.

[80] N. Qin, W. He, X.-Z. Kong et al., "Distribution, partitioning and sources of polycyclic aromatic hydrocarbons in the water-SPMsediment system of Lake Chaohu, China," Science of the Total Environment, vol. 496, pp. 414-423, 2014.

[81] Y.-B. Wang, C.-W. Liu, Y.-H. Kao, and C.-S. Jang, "Characterization and risk assessment of PAH-contaminated river sediment by using advanced multivariate methods," Science of the Total Environment, vol. 524-525, pp. 63-73, 2015.

[82] I. D. Manariotis, H. K. Karapanagioti, and C. V. Chrysikopoulos, "Degradation of PAHs by high frequency ultrasound," Water Research, vol. 45, no. 8, pp. 2587-2594, 2011.

[83] A. Liu, Y. Lang, L. Xue, and J. Liu, "Ecological risk analysis of polycyclic aromatic hydrocarbons (PAHs) in surface sediments from Laizhou Bay," Environmental Modeling \& Assessment, vol. 159, no. 1-4, pp. 429-436, 2009.

[84] E. R. Long, D. D. Macdonald, S. L. Smith, and F. D. Calder, "Incidence of adverse biological effects within ranges of chemical concentrations in marine and estuarine sediments," Journal of Environmental Management, vol. 19, no. 1, pp. 81-97, 1995.

[85] D. D. Macdonald, R. S. Carr, F. D. Calder, E. R. Long, and C. G. Ingersoll, "Development and evaluation of sediment quality guidelines for Florida coastal waters," Ecotoxicology, vol. 5, no. 4, pp. 253-278, 1996.

[86] C. A. Peters, C. D. Knightes, and D. G. Brown, "Long-term composition dynamics of PAH-containing NAPLs and implications for risk assessment," Environmental Science \& Technology, vol. 33, no. 24, pp. 4499-4507, 1999.

[87] R. Schoeny and K. Poirier, "PB-94-116571/XAB; EPA-600/R93/089 United StatesWed Feb 06 22:43:37 EST 2008NTISGRA; GRA-94-73233; EDB-94-029221English," Article ID 116571, 1993.

[88] I. C. T. Nisbet and P. K. LaGoy, "Toxic equivalency factors (TEFs) for polycyclic aromatic hydrocarbons (PAHs)," Regulatory Toxicology and Pharmacology, vol. 16, no. 3, pp. 290-300, 1992. 

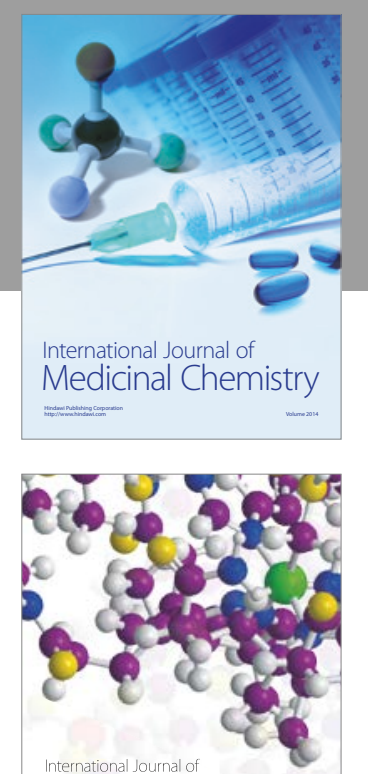

Carbohydrate Chemistry

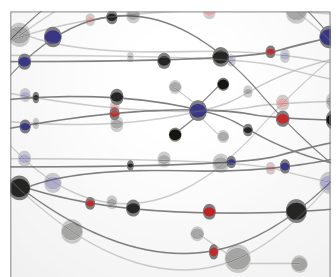

The Scientific World Journal
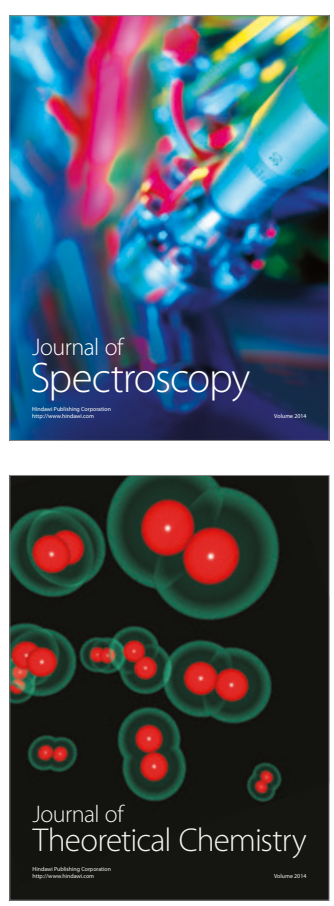
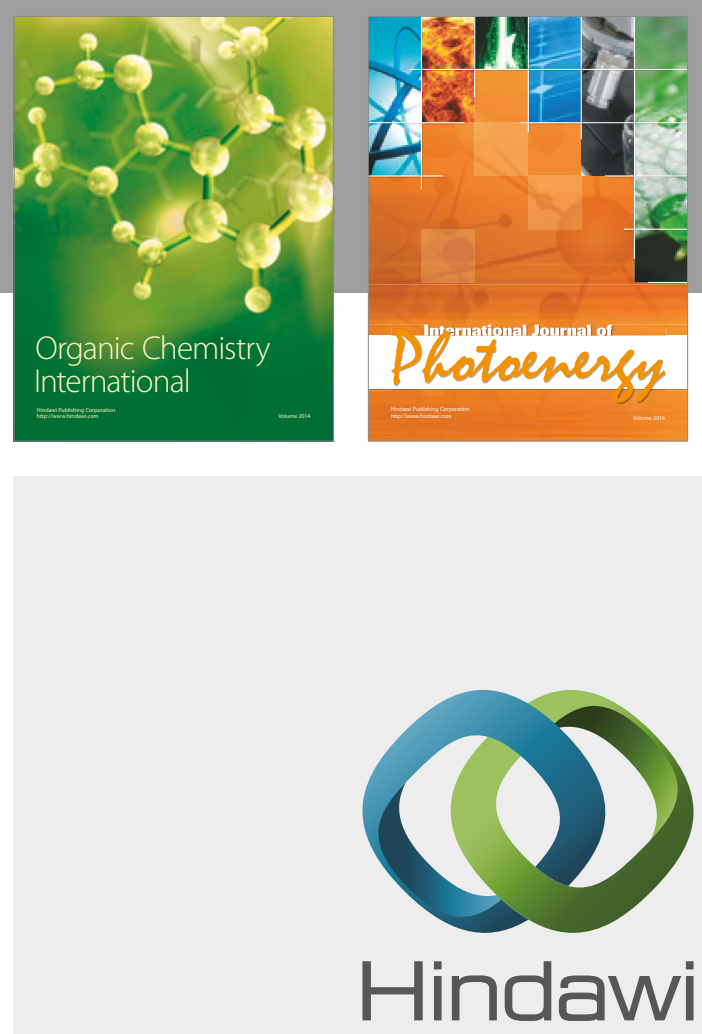

Submit your manuscripts at

https://www.hindawi.com

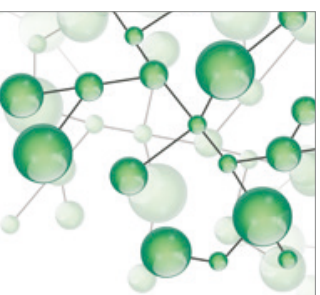

International Journal of

Inorganic Chemistry

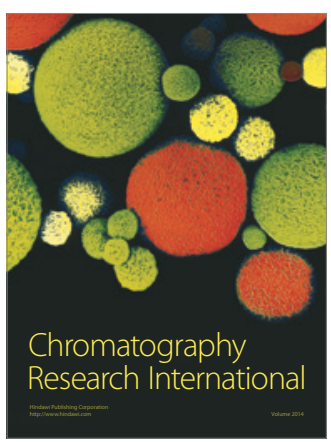

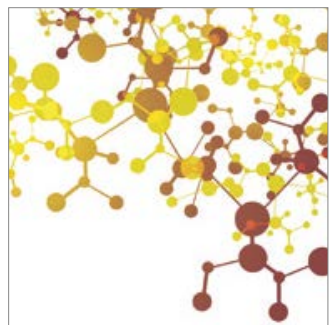

Applied Chemistry
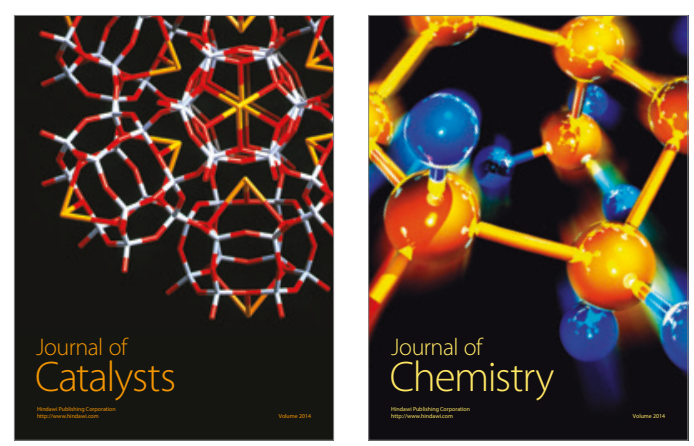
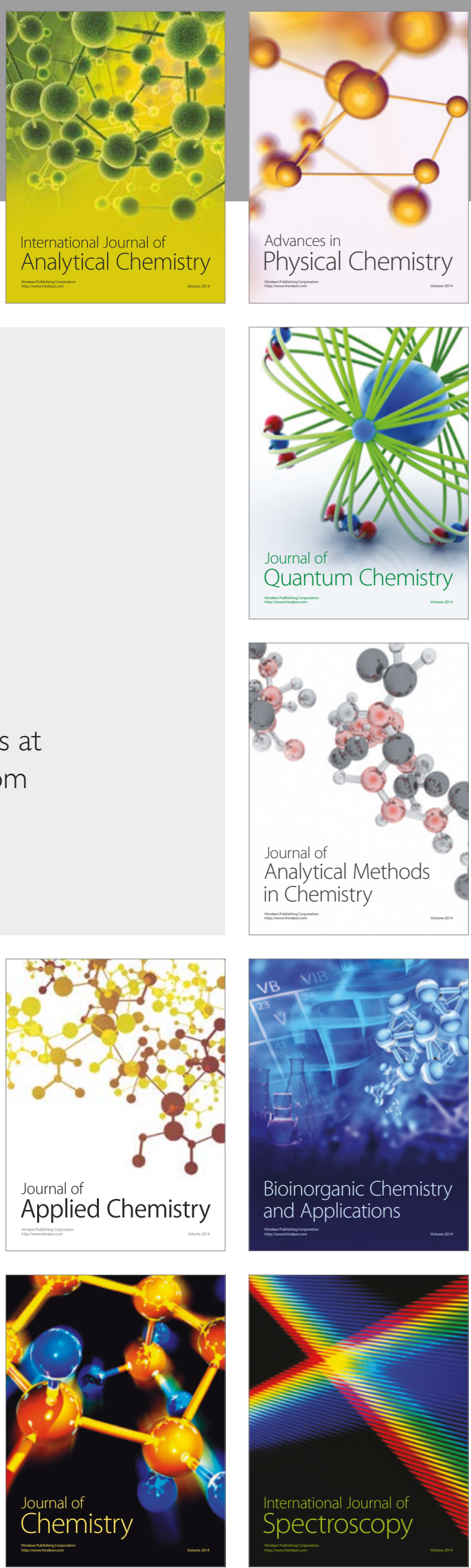